bioRxiv preprint doi: https://doi.org/10.1101/336974; this version posted June 17,2018 . The copyright holder for this preprint (which was not certified by peer review) is the author/funder, who has granted bioRxiv a license to display the preprint in perpetuity. It is made available under aCC-BY-NC-ND 4.0 International license.

\title{
Astroglial biophysics probed with a realistic cell model
}

Leonid P. Savtchenko* ${ }^{1}$, Lucie Bard*1 ${ }^{1}$, Thomas P. Jensen ${ }^{1}$, James P. Reynolds ${ }^{1}$, Igor Kraev ${ }^{2}$, Mikola Medvedev ${ }^{2}$, Michael G. Stewart ${ }^{3}$, Christian Henneberger ${ }^{1,3,4}$, Dmitri A. Rusakov ${ }^{1}$

${ }^{1}$ UCL Institute of Neurology, University College London, UK;

${ }^{2}$ The Open University, Milton Keynes, UK

${ }^{3}$ Institute of Cellular Neurosciences, University of Bonn, Germany

${ }^{4}$ German Center of Neurodegenerative Diseases (DZNE), Bonn, Germany

* Equal contribution

Correspondence: Dmitri Rusakov (d.rusakov@ucl.ac.uk) or Leonid Savtchenko (skaalsa@ucl.ac.uk)

Electrically non-excitable astroglia take up neurotransmitters, buffer extracellular $\mathrm{K}^{+}$and generate $\mathrm{Ca}^{2+}$ signals that release molecular regulators of neural circuitry. The underlying machinery remains enigmatic, mainly because the nanoscopic, sponge-like astrocyte morphology has been difficult to access experimentally or explore theoretically. Here, we have systematically evaluated the multi-scale morphology of protoplasmic astroglia to construct a realistic multi-compartmental cell model that can be biophysically interrogated in NEURON computational environment. This approach has been implemented as an astrocyte-model builder ASTRO. As a proof of concept, we explored a hippocampal astrocyte reconstructed in silico against a battery of physiological and imaging experiments. This exploration has unveiled some basic features of astroglial physiology inaccessible empirically, such as the characteristic length of membrane voltage propagation, membrane effects of local glutamate transport, spatiotemporal dynamics of intracellular $\mathrm{K}^{+}$redistribution, key $\mathrm{Ca}^{2+}$ buffering properties, and some basic relationships between free $\mathrm{Ca}^{2+}$ dynamics and experimental readout of fluorescent $\mathrm{Ca}^{2+}$ indicators.

Astroglia have emerged as an essential contributor to neural circuit signalling in the brain. In addition to the well-established mechanisms of neurotransmitter uptake and extracellular $\mathrm{K}^{+}$ buffering, electrically passive astrocytes appear competent in transducing, integrating and propagating physiological signals using intracellular $\mathrm{Ca}^{2+}$ transients ${ }^{1-3}$. Astroglial $\mathrm{Ca}^{2+}$ signals range from local hotspots to global $\mathrm{Ca}^{2+}$ waves, displaying a variety of dynamic ranges and time scales (reviewed in ${ }^{4,5}$ ). Tri-dimensional (3D) reconstructions of astroglia using electron microscopy (EM) have long revealed a fine system of nanoscopic processes ${ }^{6-10}$ that pervade the entire cell expanse ${ }^{11-13}$. Deciphering the cellular cascades and the biophysical mechanisms that shape $\mathrm{Ca}^{2+}$-dependent signalling in this sponge-like system has been a challenge ${ }^{14,15}$. A similar 
bioRxiv preprint doi: https://doi.org/10.1101/336974; this version posted June 17, 2018. The copyright holder for this preprint (which was not certified by peer review) is the author/funder, who has granted bioRxiv a license to display the preprint in perpetuity. It is made available under aCC-BY-NC-ND 4.0 International license.

challenge pertains to our understanding of how the complex geometry of astrocytes controls intracellular ionic homeostasis during rapid local influx of $\mathrm{K}^{+}$, other ions, or water molecules ${ }^{16-}$ 23

In contrast, cellular mechanisms underpinning neuronal physiology have been explored and understood in great detail. This owes to the fact that rapid advances in patch-clamp electrophysiology and cell imaging in neurons have been recapitulated and mechanistically interpreted using realistic biophysical cell models in silico. The multi-compartmental modelling of various neuronal types developed in the NEURON computational environment ${ }^{24,25}$ has been highly instrumental in advancing our knowledge about neural signal integration in the brain. There have also been numerous attempts to simulate astroglial function, based predominantly on a reductionist approach (recently reviewed in ${ }^{26,27}$ ). Aimed to answer a specific scientific question, such models would normally focus on kinetic reactions inside astroglia ${ }^{28-30}$, between astroglial and neuronal compartments ${ }^{16,31-33}$ or, alternatively, on the regulatory influences of astroglial signalling in neuronal networks ${ }^{34-36}$. These studies have provided some important insights into the biophysical basis of astroglial activity and its adaptive roles. However, their scope would normally exclude complex 3D morphology of astrocytes, intracellular concentration gradients and heterogeneous molecular fluxes, uneven landscapes of cell membrane potential, or complex relationships between $\mathrm{Ca}^{2+}$ kinetics and $\mathrm{Ca}^{2+}$-sensitive fluorescence recordings. Thus, to date there have been no attempts to integrate cellular functions of astrocyte on multiple levels, in one entity in silico, with the realistic morphology playing a major role in shaping astroglial identity ${ }^{14}$.

Our aim was therefore three-fold. First, to generate a modelling approach that recapitulates fine astroglial morphology on multiple scales while retaining full capabilities of biophysical simulations enabled by NEURON. We have therefore developed (MATLAB- and NEURONbased) computational algorithms and software that, firstly, use experimental data to recreate the space-filling architecture of nanoscopic astroglial processes, and, secondly, make this cell architecture NEURON-compatible. Our case study focused on the common type of hippocampal protoplasmic astroglia, which has been the main subject of studies focusing on synaptic plasticity and neuron-glia interactions ${ }^{37-40}$. We have combined patch-clamp electrophysiology, two-photon excitation (2PE) imaging and $2 \mathrm{PE}$ spot-uncaging, fluorescence recovery from photobleaching (FRAP), viral transduction of astroglia-targeted $\mathrm{Ca}^{2+}$ indicators in vivo, and quantitative correlational 3D EM to systematically document the multi-scale morphology and some key physiological traits of these cells. Based on these experimental constrains, we have built a multi-compartmental 3D cell model that recapitulates known features of hippocampal astrocytes and is fully integrated into the NEURON environment. Correspondingly, we have equipped the latter with additional functionalities relevant to astroglial studies, such as: generation of nanoscopic processes that fill in tissue volume; options for incorporating endfoot and gap junctions; options to arrange extracellular glutamate spot-uncaging and localised extracellular $\mathrm{K}^{+}$rises; menu for running 3D FRAP experiments; intracellular $\mathrm{Ca}^{2+}$ signal generation options; settings to replicate conditions of fluorescence imaging.

Our second objective was to implement this modelling approach as a user-friendly, interactive simulation instrument - cell model builder - capable of recreating and probing various types of astroglia in silico. Thus, we have integrated our algorithms and software as a modelling tool ASTRO, which enables an investigator to generate morphological and functional astroglial features at various scales (current version at https://github.com/LeonidSavtchenko/Astro).

Finally, as a proof of concept, we explored and probed the test-case model against experimental observations, aiming to understand some important aspects of astroglial physiology that cannot be accessed through direct experimental probing. In our case study focusing on stratum radiatum 
bioRxiv preprint doi: https://doi.org/10.1101/336974; this version posted June 17, 2018. The copyright holder for this preprint (which was not certified by peer review) is the author/funder, who has granted bioRxiv a license to display the preprint in perpetuity. It is made available under aCC-BY-NC-ND 4.0 International license.

astroglia, we have therefore evaluated key electrogenic features of the cell membrane, basic aspects of intracellular $\mathrm{K}^{+}$dynamics, the range of intracellular $\mathrm{Ca}^{2+}$ buffering capacity, and how the classical molecular machinery of $\mathrm{Ca}^{2+}$ 'puffs' and 'sparks' could explain the common observations in astroglia using fluorescence imaging of $\mathrm{Ca}^{2+}$-sensitive indicators. The results suggest that ASTRO could provide an important means for testing physiological hypotheses and causal interpretation of experimental observations pertinent to astrocytes.

\section{RESULTS}

\section{Reconstructing gross morphology of live astroglia: stem tree}

The gross morphology of CA1 astrocytes has long been documented ${ }^{11,41,42}$ pointing to the overall cell radius of $30-50 \mu \mathrm{m}$, the somatic diameter of 7-15 $\mu \mathrm{m}, 4-9$ primary processes ${ }^{11,43}$, and a main-branch ramification index (RI, probability of bifurcation per branch) of less than one 44. To elucidate the structural detail of CA1 astrocytes in situ we employed acute hippocampal slices. Individual astroglia were held in whole-cell, loaded with the bright morphological tracer Alexa Fluor 594 (Methods), and imaged using two-photon excitation (2PE; Fig. 1a,b), a procedure shown quantitatively to faithfully reveal fine cell morphology 42 .

Our modelling strategy was to start with the principal branch structure (cell 'stem tree') which could be resolved in 2PE optical images (i.e., with a diameter above the diffraction limit, 0.3-0.5 $\mu \mathrm{m}$; Fig. 1a,b) and 3D-reconstructed using computer tools that have been previously validated in neuronal studies. Here, we have employed two complementary approaches. In the first approach (Methods), the cell was imaged in a $z$-stack (Fig. 1a,b), individual images were corrected for the depth-dependent fluorescence signal decrease, identifiable stem-tree branches were traced semi-automatically and 3D-reconstructed using Simple Neurite Tracer (Fiji-ImageJ, NIH; Fig. 1c; Methods). This routine was similar to that of reconstructing 3D geometry of neuronal processes, as described widely in the literature. To store the recorded structure data in a NEURON-compatible format (Fig. 1d) we used Vaa3D (Allen Institute). Alternatively, the entire $3 \mathrm{D}$ reconstruction procedure could be carried out using commercially available Neurolucida (MBI), which provides a NEURON-compatible output.

The second approach was to build the stem tree of the 'typical' (or 'average') astrocyte from the population under study. First, the stem tree structure was taken from a digital library: in our case study we used a library neurogliaform cell (P32-DEV136, database http://neuromorpho.org), which displays gross morphology similar to that of the astrocyte (Fig. 1e, diagram). Next, the numbers and diameters of tree branches were adjusted to match experimental measurements from an experimental sample (in our case 13 astrocytes, 98 individual branches; Fig. 1e). The stem tree options also include settings to construct and explore an endfoot structure (Supplementary ASTRO User Guide, pp 20-21).

\section{The endfoot}

The endfoot surrounding blood vessels is a key morphological and functional feature of most astrocytes ${ }^{45,46}$. Because its morphology varies enormously among cells, it would seem appropriate to use direct experimental 3D reconstructions (as in Fig. 1a-d) to incorporate this feature into the cell architecture. ASTRO provides a separate menu for constructing the endfoot, connecting it to the 'main' arbour, and populating it with the nanoscopic processes (Supplementary ASTRO User Guide, pp 20-21). All nanoscopic process structures and biophysical mechanisms available in the present model builder (see sections below) could be incorporated into the endfoot. However, as it represents a self-contained, highly specialised cell 
bioRxiv preprint doi: https://doi.org/10.1101/336974; this version posted June 17, 2018. The copyright holder for this preprint (which was not certified by peer review) is the author/funder, who has granted bioRxiv a license to display the preprint in perpetuity. It is made available under aCC-BY-NC-ND 4.0 International license.

compartment, it will require a separate study to fully develop its realistic biophysical machinery and incorporate it in accord with experimental observations. Simulation tests in the present study focus therefore on the 'main' astrocyte arbour, which is thought to play a key role in astroglianeuron interactions $4,5,14,47$. Nonetheless, parts of the main arbour may include processes that surround small blood vessels.

\section{Nanoscopic astroglial processes: experimental measurements}

Once the cell stem tree was ready and NEURON-formatted, it was imported by ASTRO for the next step of morphological reconstruction: stochastic generation of nanoscopic processes. Whilst the stem tree branches can be traced in the light microscope, the bulk of astroglial morphology comprises irregularly shaped, nanoscopic processes that occur throughout the cell expanse and appear as a blur in optical images (Fig. 1a,b). 3D EM reconstructions have been used to detail the spatial organisation of these processes $10,12,13,42$. To systematically quantify such structures, we employed a correlational-EM approach based on our earlier 3D EM studies of astroglia ${ }^{10,48}$. Individual astrocytes were patched whole-cell in acute brain slices and, after cell filling with biocytine and subsequent DAB conversion, traced and reconstructed in a comprehensive serialsection survey (Methods; Supplementary Fig. 1). A recent EM study has suggested that chemical fixation via heart perfusion might lead to $30-35 \%$ volumetric tissue shrinkage and concomitant changes in fine astroglial morphology ${ }^{49}$. To minimise such effects, we used rapid fixation of thin acute slices by submersion, which was earlier shown to cause much smaller hippocampal tissue shrinkage (linear shrinkage $\sim 5 \%$ ) ${ }^{50}$ preserving the extracellular space volume fraction of $\sim 0.12$ (reviewed in ${ }^{51}$ ) which was close to $\sim 0.15$ seen under rapid cryofixation ${ }^{49}$.

Obtaining 3D reconstruction of the entire astrocyte at nanoscopic resolution is technically difficult and it may not necessarily represent the 'typical' cell. We therefore focused on the characteristic morphological features of 3D-reconstructed fragments sampled from multiple individual astrocytes from the CA1 population, as detailed earlier ${ }^{10}$ (Fig. 2a). The aim of this exploration was to extract key morphometric characteristics of the nanoscopic astrocyte processes in order to replicate such 'typical' processes in the cell model.

We therefore developed algorithms and MATLAB-based software (integrated in ASTRO) that enabled us to sample and store small astrocyte processes from our sets of 3D-reconstructed astroglial fragments (Fig. 2a,b; Supplementary ASTRO User Guide p. 12). The 3D EM reconstruction tools used here have been detailed earlier ${ }^{10}$; ASTRO can use other text-formatted files containing 3D coordinates of the cell membrane 'mesh', which is a common outcome of EM $3 \mathrm{D}$ reconstruction programs. This procedure aimed at building a database of astroglial nanoscopic structures: each process would comprise a $z$-stack (arbitrarily long) of serial $60 \mathrm{~nm}$ sections, with each section represented by reference points scattered on its 'polygonal' perimeter (Fig. 2c; Supplementary ASTRO User Guide pp. 12-13).

\section{Nanoscopic astroglial processes: NEURON-compatible transformation}

Our cell modelling approach aimed to take advantage of the NEURON computational environment enabling multiple mechanisms of cellular biophysics. However, NEURON-built cell models employ cylindrical compartments designed to follow the shape of neuronal dendrites or axons. Because astroglial processes have much less regular shapes (Fig. 2a-c), we carried out a separate investigation to establish whether and how cylindrical NEURON compartments can be used to recapitulate geometry and biophysical properties of realistic astrocyte processes. 
bioRxiv preprint doi: https://doi.org/10.1101/336974; this version posted June 17, 2018. The copyright holder for this preprint (which was not certified by peer review) is the author/funder, who has granted bioRxiv a license to display the preprint in perpetuity. It is made available under aCC-BY-NC-ND 4.0 International license.

To attempt the transition from real (3D EM-based) to NEURON-compatible shapes, we transformed individual 'polygonal' $z$-stacks of 3D-reconstructed processes into $z$-stacks of cylindrical (disk-shaped) slabs (Fig. 2d). Here, the adjacent polygonal sections with crosssection areas $S_{i}$ and $S_{i+1}$ which had an intersection area of $T_{i}$ (Fig. 2d, left and middle), were represented by two 'main' cylinder slabs with base areas $S_{i}$ and $S_{i+1}$ (termed 'leaves') plus a 'transitional' cylinder slab (termed 'stalk') with the base area $T_{i}$ (Fig. 2d, right). This transformation approximately preserved the 'diffusion bottleneck' and the surface-volume relationship of the original shape. Applying this rule systematically transformed 3Dreconstructed nanoscopic processes into the NEURON-compatible, cylinder-based shapes, with the volume and surface areas similar to those of the original shapes (Fig. 2e).

Next, we employed Monte Carlo simulations to systematically compare two key biophysical traits between the original and the NEURON-compatible shapes, the intracellular diffusion transfer rate and the dynamic electrical impedance. These tests involved 'injecting' 3000 Brownian particles into one end of the shape and counting their flux rate at the other end, with or without an electric field (Fig. 2f; example in Supplementary Movie 1). The mathematical algorithms involved were detailed, tested and validated against experimental data in our previous studies ${ }^{52-54}$. In the majority of cases, our tests showed remarkable similarity between the two shapes in their dynamic electrical and diffusion conductance properties (Fig. 2g). In the remaining cases, minor stochastic variation of the cylindrical compartment diameters achieved a similar match.

After we accumulated a representative population of cylindrical compartment radii from the 3D EM measurements (example in Supplementary Fig. 2), we also found that the biophysical match between original and transformed shapes remained when the cylindrical compartments were shuffled randomly with respect to the original shape (example in Supplementary Fig. 3). Thus, the population of nanoscopic astroglial processes could be represented in a NEURONcompatible format based on the statistical properties of 3D-reconstructed cell fragments. The sampling and transformation procedure for nanoscopic processes, as described above, has been integrated in ASTRO for investigators to explore, monitor, and validate (Supplementary ASTRO User Guide, pp. 11-18).

These measurements provided the data set for the astroglial stem tree (Fig. 1d,e) to be populated with nanoscopic processes in accord with their experimentally obtained statistics. However, this stochastically simulated 'morphogenesis' had to be further constrained by the experimentally observed tissue-filling properties of astroglia, as described below.

\section{Tissue volume fraction and astrocyte surface-to-volume ratios}

The tissue volume fraction (VF) occupied by astroglia in the hippocampal neuropil has been estimated to range between $5-10 \%{ }^{8-10,55}$. VF is a key descriptor of astrocyte morphology because astrocytes occupy adjacent tissue domains, with very little overlap ${ }^{11,56}$, while their fine processes fill the local volume in a sponge-like manner ${ }^{10,13,42}$. The distribution of astroglial VF in local tissue thus provides an important guide to the astrocyte architecture.

2PE microscopy provides a straightforward tool to monitor VF of live astroglia in situ because the fluorescent signal it collects represents emission from within a thin $(\sim 1 \mu \mathrm{m})$ layer at the focal plane (Supplementary Fig. 4a). Thus, the signal intensity produced by the dye-filled astroglia scales with the local VF occupied by one or more astroglial processes (Supplementary Fig. 4b). At the same time, the 6-10 $\mu \mathrm{m}$ wide astrocyte soma imaged in the same $1 \mu \mathrm{m}$ focal plane will correspond to $100 \%$ VF occupied by the dye-filled cytosol (at least in its brightest part which is least populated with cell organelles; Supplementary Fig. $4 \mathrm{c}){ }^{10,14}$. Thus the local- to-somatic 
bioRxiv preprint doi: https://doi.org/10.1101/336974; this version posted June 17, 2018. The copyright holder for this preprint (which was not certified by peer review) is the author/funder, who has granted bioRxiv a license to display the preprint in perpetuity. It is made available under aCC-BY-NC-ND 4.0 International license.

fluorescence intensity ratio provides direct readout of astroglial VF (Fig. 3a). We therefore first established the typical distribution of VF within individual cell arbours, as a function of the distance from the soma, for CA1 astrocytes (Fig. 3b; blue dots, mean \pm SEM for 13 cells). Next, we adjusted the computer-generated nanoscopic morphology to match this VF distribution (Fig. $3 b$, red dots).

The latter is achieved by systematically adjusting two key structural parameters in the model using ASTRO menus. The first is the average size of nanoscopic processes, determined as the number of leaves per process (up to 100; Supplementary ASTRO User Guide, Fig. 16, p. 19). The second parameter is the 'seed' density for nanoscopic processes to be planted on the stemtree branches, which normally ranges between one to three (SeedNumber variable; Supplementary ASTRO User Guide, p. 20).

Another morphological feature essential to the biophysical identity of cell processes is their surface-to-volume ratio (SVR): this value determines how the transmembrane molecular fluxes are converted into intracellular concentration changes. Careful stereological analyses of hippocampal astroglial processes using 3D quantitative EM arrive consistently at the SVR in the $15-25 \mu^{-1}$ range ${ }^{8,41,55,57,58}$. The astrocyte fragments sampled in our experiments (Fig. 2a-c) had SVRs fully consistent with this range, and the modelled nano-shapes (Fig. 2f, Supplementary Fig. 3b) faithfully reproduced this SVR range across the entire simulated cell morphology. The average SVR could be further fine-tuned in ASTRO, by adjusting the distribution of 'leaves' and 'stalks' in stochastically simulated nanoscopic protrusions (Supplementary ASTRO User Guide, pp. 21-23).

Thus, by systematically generating nanoscopic processes on the 'typical' stem tree (Fig. 1e) we arrived at what appears to be a realistic, NEURON-compatible CA1 astrocyte geometry comprising 35000-45000 individual compartments (Fig. 3c; see Supplementary Table 1 for the summary of morphological features pertinent to the present case study of CA1 astroglia). Our final test for the realistic nature of the astrocyte in silico was to see if its architecture has intracellular diffusion connectivity similar to that in live astroglia. To address this we carried out a series of experiments and simulations based on fluorescence recovery after photobleaching (FRAP), as outlined below.

\section{Internal connectivity of astroglia: experiment versus model}

FRAP protocols have long been used to gauge mobility of fluorescent molecules in live cells: the speed with which fluorescence recovers in a laser-bleached cell region reflects diffusion speed of the fluorescent molecules under study ${ }^{59}$. Notably, a 2PE FRAP technique applied to watersoluble indicator Alexa Fluor 594 was used to monitor diffusion transport through the ultrathin necks of neuronal dendritic spines ${ }^{60}$. We sought to apply a similar method to the bulk of nanoscopic astrocyte processes using line-scan FRAP: by bleaching the dye molecules within a thin cylindrical volume across the astrocyte tree, this approach should gauge average diffusion connectivity within the adjacent structures (Fig. 3d; Methods), as shown previously ${ }^{61}$.

Here, we first confirmed that the intracellular fluorescence showed full recovery well before a 60 s interval (Supplementary Fig. 5a,b), thus indicating no concomitant signal from what could be an immobile dye fraction. Furthermore, $60 \mathrm{~s}$ after the first cycle, the second FRAP cycle faithfully reproduced the time course of photobleaching and recovery displayed during the preceding FRAP cycle (Supplementary Fig. 5c). This pointed to the stability of FRAP experiments in the current settings.

We next simulated this experiment in the astrocyte model (Fig. 3e; Supplementary Movie 2) and employed an 'alternating' FRAP protocol (with laser shutter repeatedly on-off), to compare 
bioRxiv preprint doi: https://doi.org/10.1101/336974; this version posted June 17, 2018. The copyright holder for this preprint (which was not certified by peer review) is the author/funder, who has granted bioRxiv a license to display the preprint in perpetuity. It is made available under aCC-BY-NC-ND 4.0 International license.

simulation outcome with experimental observations. We found that by adjusting one free parameter in the model, the rate of Alexa line-scan photobleaching, it was possible to achieve a good match between experimental and simulated data in individual cells (example in Fig. 3f). The summary ( $\mathrm{n}=10$ recorded cells) also showed a good correspondence between recorded and simulated data for the FRAP rates at variable distances from the soma (Fig. 3g). These observations indicated that the simulated cell morphology was a good representation of the inner connectivity of real-life CA1 astrocytes.

\section{Passive electrical properties of astrocytes}

Specific membrane conductance $G_{\mathrm{m}}$ is an important determinant of electrical signal propagation in non-excitable cells, such as protoplasmic astroglia. First, we measured input resistance of live astroglia in whole-cell mode: the average value (mean \pm SEM: $2.66 \pm 0.31 \mathrm{M} \Omega, \mathrm{n}=15$; Fig. 4a) was readily consistent with the previous measurements ${ }^{37,38}$. Next, we pulled outside-out patches, estimated the patch membrane area (using the classical voltage-step method ${ }^{62}$, Methods) and recorded patch resistance: these measurements gave us the average astrocyte $G_{\mathrm{m}}$ (mean \pm SEM: $0.69 \pm 0.18 \mathrm{mS} / \mathrm{cm}^{2}$; Fig. 4b). Finally, we asked whether this experimental value of $G_{\mathrm{m}}$ (Fig. 4b) could be reproduced by an astrocyte model constrained by two other independent experimental parameters, (steady-state) input resistance $R_{i}$ and total membrane area $S_{m e m}$, in accord with Ohm's law $G_{m}=\left(S_{m e m} R_{i}\right)^{-1}$. Because modelled nanoscopic processes are generated stochastically, we have obtained a small representative sample of the astrocyte in question, by repeating the stochastic reconstruction of tissue-filling nanoscopic processes, in accord with the morphological constraints (Fig. 4c). In the sample, the cell volume (resulting from stochastic simulations) varied well within the range of $3000-4800 \mu \mathrm{m}^{3}$ characteristic of CA1 astroglia $^{11,55}$. In each cell in the sample, the free parameter $G_{\mathrm{m}}$ was adjusted until the cell $R_{i}$ matched the measured value (Fig. 4a). This test produced the average $G_{\mathrm{m}}$ value of $0.78 \pm 0.04 \mathrm{mS} / \mathrm{cm}^{2}$ (Fig. $4 \mathrm{c}$ ), which was indistinguishable from the experimental $G_{m}$ value (Fig. $4 \mathrm{~b}$ ) or the earlier empirical measurements ${ }^{18}$. Thus we have confirmed that our model reproduces 'correct' experimental values of $G_{m}$ without artificially imposing it: in other words, stochastically generated nanoscopic processes replicate realistic membrane properties of astrocytes.

To understand how far a membrane voltage/current signal propagates in electrically leaky astroglial membranes, we simulated a simple voltage-clamp experiment. This showed that large currents induce very modest astrocyte membrane depolarisation, which propagates with an electrical 3D-space constant of 30-60 $\mu \mathrm{m}$ depending on the signal frequency (Fig. 4d, left). Intriguingly, a membrane voltage signal generated at the periphery is attenuated with a smaller space constant of $25-30 \mu \mathrm{m}$ (Fig. 4d, right). This asymmetry (reported previously in nerve cells ${ }^{63}$ ) arises due to the location-dependent distribution of membrane conductance near the signal cite implying that similar signals arising at different astrocyte loci could have different membrane effects.

Because astrocyte membranes are enriched in potassium channels, in particular $\mathrm{K}_{\mathrm{ir}} 4.1$ type ${ }^{17-19}$, it would seem important to assess their contribution to the voltage signal propagation. However, the overall unit conductance of $\mathrm{K}_{\mathrm{ir}} 4.1$ in astrocytes is either compatible with or lower than the membrane current leak due to the other conductance contributors (including ion channels, exchangers, gap junctions and semi-channels) ${ }^{16,64}$. This suggests that $\mathrm{K}_{\mathrm{ir}} 4.1$ per se has little effect on the passive voltage spread profile, even though these channels play a major role in maintaining the astrocyte resting membrane potential throughout the astrocyte ${ }^{65}$. For the sake of simplicity, in our baseline test model the multiple membrane mechanisms that hold astroglial resting membrane potential near $-83 . . .-85 \mathrm{mV}$ were represented by a non-specific channel current. In these conditions, when we added evenly distributed $\mathrm{K}_{\mathrm{ir}} 4.1$, the effect on voltage 
bioRxiv preprint doi: https://doi.org/10.1101/336974; this version posted June 17, 2018. The copyright holder for this preprint (which was not certified by peer review) is the author/funder, who has granted bioRxiv a license to display the preprint in perpetuity. It is made available under aCC-BY-NC-ND 4.0 International license.

propagation was significant only when the overall $\mathrm{K}_{\mathrm{ir}} 4.1$ conductance exceeded substantially its expected physiological range (Supplementary Fig. 6a). In physiological circumstances, this scenario could be affected by changes in extracellular $\mathrm{K}^{+}$concentration $\left(\left[\mathrm{K}^{+}\right]_{\text {out }}\right)$, and by the poorly understood contributing role of other ion channels and exchangers in the astrocyte membrane (see sections below).

\section{Membrane voltage-current landscape generated by local glutamate uptake}

We next asked how the current generated by glial glutamate transporters GLT-1 in response to local glutamate release (a common physiological scenario) alters membrane potential across the cell. First, we recorded from a CA1 astrocyte (acute hippocampal slices) the current response to two-photon spot-uncaging of glutamate $(20 \mathrm{~ms})$ at variable distances from the soma (Fig. $4 \mathrm{e}$, traces). To mimic this experiment in the model, we implemented the GLT-1 transporter kinetics 66, 67 and 'scattered' the transporters uniformly on the cell surface at an effective density of $\sim 10^{4}$ $\mu \mathrm{m}^{-2} 68$. In these simulations, glutamate was applied within small spherical areas (radius $\sim 3 \mu \mathrm{m}$, duration $\sim 20 \mathrm{~ms}$ ) at quasi-random distances from the soma in silico. An excellent match between the modelled somatic current and whole-cell recording data could be obtained (Fig. 4e, plot) by adjusting one free model parameter, the amount / peak concentration of released glutamate. The model unveiled the dynamic landscape of astrocyte membrane voltage, under somatic voltage clamp (to mimic experimental conditions), which varied only within $\sim 0.2 \mathrm{mV}$ across the entire cell (Fig. 4f; Supplementary Movie 3).

To reiterate on the electric properties of astroglia, these data show quantitatively how a local current hotspot in the electrically leaky astroglial membrane stays highly localised, with little effect on the voltage landscape (Fig. 4f). Because of the low baseline membrane resistance, this scenario remained only weakly affected by adding the voltage-dependent $\mathrm{K}_{\mathrm{ir}} 4.1$ conductance ${ }^{16}$, ${ }^{64}$ unless the latter exceeded its physiological range (Supplementary Fig. 6b-d). Again, this test dissects the role of $\mathrm{K}_{\mathrm{ir}} 4.1$ in otherwise unchanged cell conditions (e.g., resting membrane potential stays unchanged as we artificially add $K_{\mathrm{ir}} 4.1$ ) whereas removal of $K_{\mathrm{ir}} 4.1$ in real cells could lead to complex physiological effects ${ }^{65,69}$. In any case, these tests suggest that local glutamate transporter currents on their own cannot significantly depolarise astrocyte membrane away from the region of active transport.

\section{Potassium uptake and redistribution inside astroglia}

Rapid uptake of the neural activity-induced excess of extracellular $\mathrm{K}^{+}$and its intracellular redistribution are essential functions of brain astroglia ${ }^{18-20,46,70}$. Several elegant biophysical models have shed light on the kinetics and the tissue-wide spread of this process $16,46,71$. Modelling with ASTRO should help to understand the detailed spatiotemporal dynamics of $\mathrm{K}^{+}$ redistribution inside individual astroglial compartments, on the microscopic scale.

As a proof of concept, we simulated a physiological scenario in which extracellular $\left[\mathrm{K}^{+}\right]$ ([ $\left.\mathrm{K}^{+}\right]_{\text {out }}$ ) was elevated, from resting $3 \mathrm{mM}$ to $10 \mathrm{mM}$ (level often associated intense local excitatory activity ${ }^{72}$ ), inside a $20 \mu \mathrm{m}$ wide spherical region of the astrocyte-containing tissue, for 2 seconds (Fig. 5a). The cell model was populated with $\mathrm{K}_{\mathrm{ir}} 4.1$ channels with the kinetics described earlier ${ }^{16}$, and unit conductance of $0.1 \mathrm{mS} / \mathrm{cm}^{2}$. Upon $\left[\mathrm{K}^{+}\right]_{\text {out }}$ elevation, these channels were activated homogeneously inside the $20 \mu \mathrm{m}$ area (peak current $0.01 \mathrm{~mA} / \mathrm{cm}^{2}$; not shown). This prompted local $\mathrm{K}^{+}$entry, leading to a local increase in $\left[\mathrm{K}^{+}\right]_{\mathrm{in}}$, which dissipated inside the cell over several seconds after $\left[\mathrm{K}^{+}\right]_{\text {out }}$ returned to $3 \mathrm{mM}$ (Fig. $4 \mathrm{~b}$ ). During the period of elevated $\left[\mathrm{K}^{+}\right]_{\text {out }}$, the membrane potential landscapes reflected very slight depolarisation generated by $\mathrm{K}_{\mathrm{ir}} 4.1$ (Fig. 5c), not dissimilar to the slight depolarisation arising from local glutamate uptake 
bioRxiv preprint doi: https://doi.org/10.1101/336974; this version posted June 17, 2018. The copyright holder for this preprint (which was not certified by peer review) is the author/funder, who has granted bioRxiv a license to display the preprint in perpetuity. It is made available under aCC-BY-NC-ND 4.0 International license.

(Fig. 4f). These data provided a quantitative illustration of extracellular $\mathrm{K}^{+}$buffering and its intracellular redistribution, suggesting that the latter is likely to be controlled by local $\mathrm{K}^{+}$efflux, in particular through $\mathrm{K}_{\mathrm{ir}} 4.1$. Again, although $\mathrm{K}_{\mathrm{ir}} 4.1$ appear to represent a major, potentialforming membrane astrocyte conductance ${ }^{16,64,65}$, and further experimental studies are required to understand whether the effect of other membrane mechanisms has any significant contribution to $\mathrm{K}^{+}$buffering.

To further dissect the contributing role of active $\mathrm{K}^{+}$extrusion mechanisms, such as pumps and ion exchangers, we carried out similar tests $\left(\mathrm{K}^{+}\right.$within a $\sim 15 \mu \mathrm{m}$ spherical area, over $200 \mathrm{~ms}$ at a current density of $1 \mathrm{~mA} / \mathrm{cm}^{2}$ ), but with the active removal of intracellular $\mathrm{K}^{+}$by a first-order pump (this may also reflect gap-junction escape) and no contribution from $\mathrm{K}_{\mathrm{ir}} 4.1$ channels (Supplementary Fig. 7). Again, the model captured the dynamic spatial landscape of $\left[\mathrm{K}^{+}\right]_{\text {in }}$, with and without any extrusion mechanisms, confirming that local $\mathrm{K}^{+}$efflux could efficiently limit the spatial spread of $\left[\mathrm{K}^{+}\right]_{\text {in }}$ elevations (Supplementary Fig. 7).

\section{Gap junctions and hemichannels}

Gap junctions comprising of adjoined connexin proteins connect neighbouring astroglia: this enables electrical current leak and the diffusional flow of molecules across the tissue-wide astroglial syncytium ${ }^{40,73}$. In addition, astroglial membranes are enriched in connexin hemichannels permitting transfer of large molecules between the cytoplasm and the extracellular medium ${ }^{74}$. To understand their contribution to the membrane conductance in our tests, we blocked them with carbenoxolon (CBX, bath applied $50 \mu \mathrm{M})$. This increased cell input resistance by $\sim 30 \%$ (Supplementary Fig. 8), consistent with the previous measurements in CA1 astrocytes ${ }^{75}$.

To enable theoretical probing of these features, we have incorporated basic gap junction options in the ASTRO menu, both as electric conductance and as a diffusion channel (Methods; Supplementary ASTRO User Guide, pp. 18, 26-28). For the sake of clarity, however, simulation examples in the present study considered gap junctions and hemichannels as a constituent contributor to membrane conductance. Dissecting their precise functional roles will require further dedicated experimental studies aiming to quantify their biophysical properties as well as their 3D distribution across the astrocyte tree ${ }^{76}$.

\section{Astroglial calcium waves: probing the impact of calcium buffering}

Astrocytes have long been known to generate non-dissipative $\mathrm{Ca}^{2+}$ waves communicating physiological signals within and among cells ${ }^{1,2}$. The underlying cellular mechanisms are thought to engage a variety of $\mathrm{Ca}^{2+}$ stores, channels, and pumps involving endoplasmic reticulum and mitochondria (reviewed in $5,15,77$ ). The key molecular machinery here appears to engage $\mathrm{Ca}^{2+}$-dependent $\mathrm{Ca}^{2+}$ release from $\mathrm{Ca}^{2+}$ stores controlled by inositol 1,4,5-trisphosphate $\left(\mathrm{IP}_{3}\right)$ receptors and possibly ryanodine receptors, involving a highly non-linear, sometimes bellshaped, dependence between their activity and local $\mathrm{Ca}^{2+}$ concentration ${ }^{78-81}$. More recently, significant $\mathrm{Ca}^{2+}$ transients have been detected in astroglia lacking $\mathrm{IP}_{3}$ receptors ${ }^{82-84}$, although cell-engulfing, 'global' waves seem to involve $\mathrm{IP}_{3}$ action (reviewed in ${ }^{4}$ ). In all such cases, a critical parameter that controls intracellular $\mathrm{Ca}^{2+}$ signal propagation is the $\mathrm{Ca}^{2+}$ buffering capacity of the cytosol ${ }^{85}$, the feature explored in detail in nerve cells ${ }^{86}$.

The biophysical mechanisms of $\mathrm{Ca}^{2+}$ oscillations and $\mathrm{Ca}^{2+}$ diffusion and buffering are enabled in the NEURON environment by default, based on the kinetics of $\mathrm{IP}_{3}$ signalling which has been well explored (Methods). In addition, ASTRO package incorporates two alternative $\mathrm{IP}_{3^{-}}$ 
bioRxiv preprint doi: https://doi.org/10.1101/336974; this version posted June 17, 2018. The copyright holder for this preprint (which was not certified by peer review) is the author/funder, who has granted bioRxiv a license to display the preprint in perpetuity. It is made available under aCC-BY-NC-ND 4.0 International license.

dependent $\mathrm{Ca}^{2+}$ mechanisms described earlier in theoretical studies of astroglial $\mathrm{Ca}^{2+}$ signalling 26, 28, 87. In the default configuration, four key parameters control intracellular $\mathrm{Ca}^{2+}$ wave dynamics: resting (or average) $\mathrm{IP}_{3}$ concentration $C_{\mathrm{IP} 3}$, resting $\mathrm{Ca}^{2+}$ level $\left[\mathrm{Ca}^{2+}\right]_{0}$, concentration $[B]$ of endogenous $\mathrm{Ca}^{2+}$ buffer, and buffer affinity (dissociation constant) $K_{D}$. Most studies constrain $C_{\mathrm{IP} 3}$ within $0.5-3 \mu \mathrm{M}^{88-90}$. As for $\left[\mathrm{Ca}^{2+}\right]_{0}$, we were able to measure it directly using time-resolved fluorescence microscopy pointing to the range of $50-100 \mathrm{nM}^{91}$. In contrast, $[B]$ and $K_{D}$ of endogenous $\mathrm{Ca}^{2+}$ buffers can vary widely across cell types and thus remain unknown yet essential determinants of intracellular $\mathrm{Ca}^{2+}$ dynamics in astroglia.

Similar to the biophysical models of other cell types ${ }^{88-90}$, we found that $\mathrm{Ca}^{2+}$ waves in the modelled astroglia could be generated over a wide (physiologically plausible) range of the aforementioned parameters. To dissect and illustrate the impact of $\mathrm{Ca}^{2+}$ buffering on $\mathrm{Ca}^{2+}$ wave propagation per se, we compared the wave dynamics in modelled cells with and without a relatively small amount $(10 \mu \mathrm{M})$ of mobile $\mathrm{Ca}^{2+}$ buffer added (Fig. 6a; see legend for parameter detail; Supplementary Movie 4). It appeared that adding the buffer reduced the speed and amplitude of $\left[\mathrm{Ca}^{2+}\right]$ waves significantly (Fig. 6a). Intriguingly, this also implies that increased $\mathrm{Ca}^{2+}$ buffering in these conditions leads to longer periods of elevated intracellular $\left[\mathrm{Ca}^{2+}\right]$. Again, an accurate interpretation of such results requires a dedicated experimental study.

\section{Astroglial calcium waves: assessing cell calcium-buffering capacity in vivo}

Because there is an ongoing debate on whether astroglial $\mathrm{Ca}^{2+}$ waves seen in acute slices or in culture are fully physiological ${ }^{92}$, we sought to document such waves in live animals, taking advantage of our earlier protocols of astroglial $\mathrm{Ca}^{2+}$ monitoring in vivo ${ }^{91}$. However, imaging intracellular $\mathrm{Ca}^{2+}$ waves in the hippocampus in vivo involves mechanically invasive methods the impact of which on astroglial function is not fully understood. We therefore imaged somatosensory cortex astroglia (accessible with intact brain surface), which appear to show some remarkable similarities in their major morphological features and territorial volumes, across ages, with hippocampal astrocytes ${ }^{93}$.

We asked therefore whether $[B]$ and $K_{D}$ for cortical astroglia could be assessed by matching the $\mathrm{Ca}^{2+}$ wave dynamics documented in situ with the modelled outcome. To reduce the concomitants of ex vivo preparations and to take advantage of our earlier measurements of astroglial $\mathrm{Ca}^{2+}$ in $v_{i v o}{ }^{91}$, we recorded spontaneous activity of astrocytes in the rat somatosensory cortex using a virus-transfected $\mathrm{Ca}^{2+}$ indicator expressed under a GFAP promoter. To minimise the spatiotemporal filtering effects of free-diffusing $\mathrm{Ca}^{2+}$ indicators we used plasma-membrane tethered GCaMP6f, with a $\sim 50 \mathrm{~ms} \mathrm{Ca}^{2+}$-sensitive fluorescence response time ${ }^{94}$. The animals were anaesthetized, to limit bursts of sensory input-evoked regional $\mathrm{Ca}^{2+}$ rises that could be mistaken for self-propagating $\mathrm{Ca}^{2+}$ waves ${ }^{95}$. Gross morphology of astrocytes was monitored in a red channel using bolus-loading of sulforhodamine 101 (SR101) via a pressurized patch-pipette (Fig. 6b), as described previously ${ }^{91}$.

In baseline conditions, we could readily detect spontaneous $\mathrm{Ca}^{2+}$ waves that appear to engulf entire individual cells (spreading over 10-20 $\mu \mathrm{m}$ in the XY plane with an average frequency of $\sim 5.4$ waves a minute over a 160 x $160 \mu \mathrm{m}$ ROI; Fig. 6c, top panels; Supplementary Movie 5), in good correspondence with previous observations ${ }^{96}$. The time first derivative of the fluorescence transients could reveal the spreading wave fronts of these signals (Fig. 6c, bottom panels). Thus, only the waves spreading in a clear centrifugal manner (as in Fig. 6c) were selected, to ensure that they represent single-cell regenerative events rather than signals evoked by synchronous external influences. 
bioRxiv preprint doi: https://doi.org/10.1101/336974; this version posted June 17, 2018. The copyright holder for this preprint (which was not certified by peer review) is the author/funder, who has granted bioRxiv a license to display the preprint in perpetuity. It is made available under aCC-BY-NC-ND 4.0 International license.

Our measurements indicated that such waves propagated with an average radial speed of $3.94 \pm$ $0.16 \mu \mathrm{m} / \mathrm{s}$ (mean $\pm \mathrm{SEM}, \mathrm{n}=54$ events). Intriguingly, this speed appears significantly lower than that of the stimulus-induced astroglial $\mathrm{Ca}^{2+}$ waves in brain slices or in culture $(15-25 \mu \mathrm{m} / \mathrm{s}$, reviewed in ${ }^{97}$ ). The relatively fast speed of $\mathrm{Ca}^{2+}$ waves in slices or in culture could be because the exogenous stimulus, such as agonist bath or puff application, could prompt a synchronous receptor response over the entire cell expanse. Similarly, in the awake animals, we could detect local waves resembling those under anaesthesia, albeit at a lower frequency (and apparently lower magnitude), in between large synchronous $\mathrm{Ca}^{2+}$ elevations engulfing entire regions (Supplementary Movie 6). Again, the possible overlap of such prevalent synchronous events and 'genuine' one-cell waves made the anesthetised animals a preferred choice to assess $\mathrm{Ca}^{2+}$ buffering properties of astroglia.

In our tests, intracellular $\mathrm{Ca}^{2+}$ waves reported by the GCaMP6f fluorescence could be readily reproduced in an astrocyte model in response to an instantaneous $\mathrm{Ca}^{2+}$ rise $(5 \mu \mathrm{M}$ for $0.1 \mathrm{~ms})$ near the soma (Fig. 6d). Although we could observe simulated waves over a wide range of buffering parameters, the experimentally documented propagation speed corresponded to only certain values of $[B]$ and $K_{D}$ (Fig. 6e): for the plausible $K_{D}$ range of $0.2,0.5,1$ and $2 \mu \mathrm{M}$ the corresponding $[B]$ were $200,260,340$, and $510 \mu \mathrm{M}$, respectively. The empirical relationship between these $[B]$ and $K_{D}$ values was almost perfectly linear (in $\left.\mu \mathrm{M}\right)$ : $[B]=170\left(1+K_{D}\right)$. This simple formula captures the buffering properties of cortical astrocytes, also suggesting the theoretical lower-limit $\mathrm{Ca}^{2+}$ buffer concentration of $\sim 170 \mu \mathrm{M}$ (ignoring the residual buffering effect of membrane-bound GCaMP6f).

\section{Decoding astroglial $\mathrm{Ca}^{2+}$ signals: from recorded fluorescence to the underlying $\mathrm{Ca}^{2+}$ dynamics}

Historically, the relatively slow, global $\mathrm{Ca}^{2+}$ elevations (as in Fig. 6c) have been the most prominent indicator of astroglial activity. Recent advances in high-sensitivity $\mathrm{Ca}^{2+}$ imaging have revealed faster and more local $\mathrm{Ca}^{2+}$ signals which are prevalent in small processes and probably engage compartmentalised and diverse cell functions (reviewed in ${ }^{4,15,98,99}$ ). In most cases, such observations rely on high-affinity $\mathrm{Ca}^{2+}$ indicators, thus providing only a crude reference to the underlying $\mathrm{Ca}^{2+}$ dynamics ${ }^{14}$. To translate recorded fluorescence into the intracellular $\mathrm{Ca}^{2+}$ dynamics, one has to model in silico $\mathrm{Ca}^{2+}$ entry, diffusion, and the buffering by endogenous proteins and $\mathrm{Ca}^{2+}$ indicators, as shown in numerous studies of nerve and muscle cells (reviewed in $81,100-102$ ).

We therefore asked to what degree $\mathrm{Ca}^{2+}$ imaging data commonly recorded in astroglia in situ shed light on the underlying intracellular $\mathrm{Ca}^{2+}$ dynamics. First, we imaged CA1 astrocytes loaded whole-cell with Fluo-4 in acute hippocampal slices: these cells showed robust spontaneous $\mathrm{Ca}^{2+}$ activity consistent with previously reported data ${ }^{12,38,103}$ (Fig. 7a,b; Supplementary Movie 7).

While the precise origin of astrocyte $\mathrm{Ca}^{2+}$ hotspots is still poorly understood, there has been a large body of work exploring the basic machinery of $\mathrm{Ca}^{2+}$ oscillations for other cell types ${ }^{80,81 \text {, }}$ 104. The key features emerging from these studies are the occurrence of detectable microscopic $\mathrm{Ca}^{2+}$ domains $\left(0.5-5 \mu \mathrm{m}\right.$ apart $\left.{ }^{80,105}\right)$ represented by clusters of stochastically activated $\mathrm{Ca}^{2+}$ channels (such as $\mathrm{IP}_{3}$ or ryanodine receptors), with the agonist-dependent mean opening time of 2-20 ms, peak amplitude of $\sim 5 \mathrm{pA}$, and an inter-opening interval varying between zero (overlap, multi-channel opening) and $\sim 50 \mathrm{~ms}{ }^{106-108}$. Stochastic activation of this system produces local $\mathrm{Ca}^{2+}$ 'sparks' (associated with ryanodine receptors clusters) or 'puffs' (associated with $\mathrm{IP}_{3^{-}}$ receptor clusters) ${ }^{80}$, typically with a puff event frequency of $0.1-2 \mathrm{~Hz}{ }^{30,109}$, leading, in certain 
bioRxiv preprint doi: https://doi.org/101101/336974; this version posted June 17, 2018. The copyright holder for this preprint (which was not certified by peer review) is the author/funder, who has granted bioRxiv a license to display the preprint in perpetuity. It is made available under aCC-BY-NC-ND 4.0 International license.

conditions, to formation of global $\mathrm{Ca}^{2+}$ activity ${ }^{104}$. Genetic deletion of astroglial $\mathrm{IP}_{3}$ receptors has unveiled other important sources of spontaneous $\mathrm{Ca}^{2+}$ activity, such as mitochondria and $\mathrm{Ca}^{2+}$ channels ${ }^{82-84}$. However, the exact kinetic properties of such $\mathrm{Ca}^{2+}$ sources remain to be established.

In our example, in keeping with the basic paradigm, we have scattered local clusters of $\mathrm{Ca}^{2+}$ channels ( $\mathrm{IP}_{3}$ receptor type) along several branches of the modelled astrocyte, 1-5 $\mu \mathrm{m}$ apart (Fig. $7 \mathrm{c}$ ), within a $\sim 20 \mu \mathrm{m}$ area of interest: $\mathrm{Ca}^{2+}$ activity outside the area was of little consequence because of the comprehensive diffusional dissipation in the absence of global $\mathrm{Ca}^{2+}$ events. The simulated astrocyte was 'filled' with $150 \mu \mathrm{M}$ freely diffusing Fluo-4 $\left(k_{o n}=600 \mathrm{mM}^{-1} \mathrm{~ms}^{-1}, k_{o f f}=\right.$ $21 \mathrm{~ms}^{-1}$ ) and the endogenous buffer in accord with our estimation (Fig. 6d, we used $200 \mu \mathrm{M}, K_{D}$ $=0.2 \mu \mathrm{M}$; other combinations consistent with Fig. $6 \mathrm{~d}$ data produced similar results).

Next, we explored simulated channel openings, within and among $\mathrm{Ca}^{2+}$ channel clusters, over the plausible range of their characteristic frequencies (see above; illustrated in Fig. 7d).

Astrocyte $\mathrm{Ca}^{2+}$ fluorescence was represented by the concentration of Ca-bound Fluo-4 and recorded at four arbitrarily selected points in the area of interest (Fig. 7c; Supplementary Movie 8 ). We found that at the average interval between channel openings of $\sim 3 \mathrm{~ms}$ within clusters, and $\sim 7 \mathrm{~s}$ among clusters, the simulated fluorescence signals (Fig. 7e) were similar to the experimental recordings (Fig. 7b). The intracellular $\mathrm{Ca}^{2+}$ dynamics underlying these signals was readily available in the model (Fig. 7f). Clearly, obtaining accurate data on the intracellular $\mathrm{Ca}^{2+}$ dynamics would require systematic experimental probing involving varied $\mathrm{Ca}^{2+}$ buffering conditions and a molecular dissection of the $\mathrm{Ca}^{2+}$ cascades involved. However, the example shown here indicates that the classical molecular machinery of $\mathrm{Ca}^{2+}$ signalling long explored in other cell types ${ }^{80,81,104-106,108}$ could generate intracellular $\mathrm{Ca}^{2+}$ activity consistent with $\mathrm{Ca}^{2+}$ imaging data collected in astrocytes. Our further exploration of $\mathrm{IP}_{3}$ arrangement within local astrocyte branches revealed a complex relationship between inter-cluster distances, spontaneous $\mathrm{Ca}^{2+}$ activity and its fluorescent-indicator readout (see below).

\section{Variations in cell features: probing an impact on astroglial function}

One of the advantages of having a realistic cell model is the possibility to dissect an impact of specific cellular features or physiological environment (which might be inaccessible for experimental manipulation) on cell's behaviour. This strategy could also reveal whether certain feature combinations make the modelled cell unstable. To illustrate such an approach, we carried out a selection of example tests in which some key functional traits of modelled cells were monitored against changes in model parameters.

First, to see how strongly gross morphology of the astrocyte could influence its biophysics, we compared two different modelled cells, one with the stem tree reconstructed from an in situ experiment (Fig. 1a-d), and the 'typical CA1 astrocyte', with the tree branches adjusted to match the average features of CA1 astrocytes (Fig. 1e). The two modelled cells featured different stem trees but were populated with nanoscopic processes based on the same volume fraction, size, and shape distributions (as illustrated in Figs 2-3). Simulations revealed only subtle differences between the cells in their passive voltage spread, input resistance, or $\mathrm{Ca}^{2+}$ wave generation (Supplementary Fig. 9). In a similar context, simulating astrocyte 'swelling' by $\sim 20 \%$ (by evenly increasing the width of cell processes throughout) had only moderate consequences (Supplementary Fig. 10). These examples suggest a relatively narrow range of effects arising from morphological variations per se, when all other features remain unchanged.

We next asked how the effective intracellular diffusion coefficient - for instance, for molecules dialysed in whole-cell mode - would affect the molecule equilibration time in the astrocyte. Our 
bioRxiv preprint doi: https://doi.org/10.1101/336974; this version posted June 17, 2018. The copyright holder for this preprint (which was not certified by peer review) is the author/funder, who has granted bioRxiv a license to display the preprint in perpetuity. It is made available under aCC-BY-NC-ND 4.0 International license.

simulations mimicking whole-cell dialysis through the soma provide a quantitative illustration of how reducing diffusivity from 0.6 to $0.05 \mu \mathrm{m}^{2} / \mathrm{ms}$ (values characterising obstacle-free diffusion of small ions and 2-3kDa molecules, such as Alexa 488-dextran, respectively) slows down dye equilibration (Supplementary Fig. 11). These examples, however, should be further tested against experimental data, mainly because larger molecules tend to undergo significant steric and viscous hindrance inside small cell compartments (hence diffuse disproportionately slower) ${ }^{110}$. Also, these example data ignore the possible diffusion escape of the smaller molecules through gap junctions: this feature could be added through the ASTRO menu (Supplementary ASTRO User Guide, pp. 27-28) once the gap junction sink parameters have been experimentally constrained.

Finally, we used simulation settings described in Fig. 7 to ask how the clustering of the $\mathrm{IP}_{3^{-}}$ dependent $\mathrm{Ca}^{2+}$-signalling mechanisms affects local $\mathrm{Ca}^{2+}$ activity in astrocyte branches. It appears that spreading this signalling mechanism into individual (equally spaced) clusters, with the same total amount of the $\mathrm{IP}_{3}$ activity, facilitates triggering of significant de novo $\mathrm{Ca}^{2+}$ events, which could feature prominently in fluorescent recordings (Supplementary Fig. 12).

\section{DISCUSSION}

\section{Realistic astrocyte models: rationale}

The present study sought to create a simulation tool ASTRO that would allow scientists to explore and test mechanistic hypotheses pertinent to complex astroglial physiology, on the scale from nanoscopic processes to the entire cell expanse. Biophysical cell models with realistic morphology have been important for a better understanding of neural function yet there have hitherto been no similar tools available to study astroglia. We therefore aimed at filling this knowledge gap.

In particular, we tried to show specific examples where the ASTRO built model could evaluate how fast molecular diffusion exchange occurs within the astrocyte; whether and how local electric events can control voltage-sensitive membrane mechanisms across the astrocyte; how fast ions such as $\mathrm{K}^{+}$could enter the cell through known channels and how fast they could equilibrate inside it; what key cellular parameters control astrocyte $\mathrm{Ca}^{2+}$ waves; how one should interpret $\mathrm{Ca}^{2+}$ imaging recordings.

\section{Building astrocyte models with ASTRO}

The task of recreating astroglial morphology in silico included three steps. The first step was to construct a 'stem tree' based on experimental documentation of main astrocyte branches that are readily identifiable in the microscope. This procedure is similar to the commonly used 3D reconstructions of fluorescently labelled nerve cells using $z$-stacks of their optical sections. The second step, which was the key methodological challenge here, was to recreate the complex morphology of numerous nanoscopic astroglial processes that pervade the synaptic neuropil. To address this, we developed algorithms and computational tools with the aim, firstly, to document and quantify such processes using an empirical 3D EM database, and secondly, to transform the recorded shapes into NEURON-compatible, cylinder-compartment-based shapes, with matched biophysical properties. The latter match was to be verified using specific Monte Carlo simulation tests (for diffusion and electrodiffusion) incorporated in the software. The recorded shapes provided all the key statistics characterising the shapes of nanoscopic astroglial processes in the model. 
bioRxiv preprint doi: https://doi.org/10.1101/336974; this version posted June 17, 2018. The copyright holder for this preprint (which was not certified by peer review) is the author/funder, who has granted bioRxiv a license to display the preprint in perpetuity. It is made available under aCC-BY-NC-ND 4.0 International license.

Thus, the third step was to populate the modelled stem tree with the stochastically generated nanoscopic processes, in accord with their morphometric characteristics obtained as outlined above. The essential experimental constraint here was the tissue volume fraction occupied by astroglial processes, which we and others could measure directly using either 2PE microscopy or 3D EM. Because neighbouring astrocytes display a negligible overlap in the tissue volume, this quantity faithfully reflects the space-filling properties of individual astroglia. We therefore stochastically generated individual processes on dendritic branches until their bulk, within the cell expanse, matched the empirically measured astroglial tissue volume fraction. This procedure completed the architecture of the modelled astrocyte: the model could now be explored using NEURON simulation environment which we equipped with several additional functions specific to astroglial exploration.

In our case study, we obtained and incorporated detailed morphological data on hippocampal astroglia in area CA1, recreated the 'typical' cell in silico, and explored it against experimental observations involving patch-clamp electrophysiology and 2PE imaging in situ. This investigation has shed light on some features of astroglial physiology that have not been attainable in experimental measurements. Our simulations predict that membrane local glutamate uptake or $\mathrm{K}^{+}$intake via $\mathrm{K}_{\mathrm{ir}} 4.1$ generate only very small membrane depolarisation across the astrocyte. It appears that transient rises of extracellular $\left[\mathrm{K}^{+}\right]$lead to relatively small relative changes of intra-astroglial $\left[\mathrm{K}^{+}\right]$, which dissipate relatively quickly, within one cell, helped by efficient local $\mathrm{K}^{+}$efflux through $\mathrm{K}_{\mathrm{ir}} 4.1$ channels. Our tests illustrated that relatively small changes in the $\mathrm{Ca}^{2+}$ buffering properties of astroglia might lead to significant changes in the spread of regenerative intracellular $\mathrm{Ca}^{2+}$ signals. The modelling also suggested that the classical molecular mechanisms of rapid $\mathrm{Ca}^{2+}$ sparks and hotspots described in other cell types could be consistent with the experimental observations of the apparently slow $\mathrm{Ca}^{2+}$ activity documented using common $\mathrm{Ca}^{2+}$-sensitive fluorescent indicators.

\section{Exploring astrocyte function and astroglia-synapse exchange}

In broad terms, the astrocyte modelling approach presented here serves several general purposes. Firstly, to recapitulate complex astrocyte morphology at multiple scales, thus providing a first structurally realistic representation of these cells, as well as the possibility to explore the effects of morphological changes on cell function. Secondly, to assess whether experimental results obtained in astroglia, their interpretation or the underlying hypotheses are biophysically plausible, by reproducing them in the realistic model. Thirdly, to understand microscopic spatiotemporal profiles of ion currents, molecular fluxes, and other events that cannot be monitored or registered experimentally. Finally, to predict the relationships between specific cellular features (morphology, $\mathrm{Ca}^{2+}$ buffering, channel current density, molecular transport, etc.) and physiological phenotype registered experimentally.

ASTRO has direct access to the full library of biophysical mechanisms pertinent to synaptic and non-synaptic receptors enabled by NEURON. Therefore, arbitrary patterns of synaptic influences throughout the astrocyte tree could be simulated. In addition, excitatory synaptic function could be mimicked using the glutamate uncaging menu in ASTRO. Clearly, the investigator is supposed to incorporate a specific, experimentally constrained kinetic mechanism of the synaptically-induced receptor action of interest, be this $\mathrm{IP}_{3}$ release, $\mathrm{Ca}_{2+}$ entry, $\mathrm{K}^{+}$fluxes, etc. Judging by the numerous examples from neuronal physiology, each such quest will require a separate, dedicated study combining experimental tests with theoretical probing in the model.

Thus, it is important to stress that our main aim here was not to present one fixed astrocyte model. Instead, we sought to create an interactive modelling tool ASTRO that would enable 
bioRxiv preprint doi: https://doi.org/10.1101/336974; this version posted June 17, 2018. The copyright holder for this preprint (which was not certified by peer review) is the author/funder, who has granted bioRxiv a license to display the preprint in perpetuity. It is made available under aCC-BY-NC-ND 4.0 International license.

researchers to test biophysical causality of their experimental observations in astroglial types of interest. The examples presented here provide illustrations of how such tasks could be accomplished. In words, ASTRO is not a 'frozen' tool: as new investigatory tasks emerge, it is to be upgraded and equipped with further modelling instruments. The current version of ASTRO and its detailed user's manual are accessible for download and exploration at https://github.com/LeonidSavtchenko/Astro.

\section{AUTHORS CONTRIBUTIONS}

D.A.R., L.P.S. and C.H. conceived the study; L.P.S. developed and implemented the modelling approach and its computing environment; C.H. designed and carried out morphometric studies ex vivo; C.H. and L.B. carried out patch-clamp and imaging experiments and analyses ex vivo; T.J. carried out some imaging experiments ex vivo, J.P.R. carried out imaging experiments in vivo; I.K., M.M., and M.G.S. designed and carried our quantitative EM studies; D.A.R. narrated the study, carried out 3D cell reconstructions, analyses and wrote the paper which was subsequently contributed to by all the authors.

\section{ACKNOWLEDGEMENTS}

This study was supported by Wellcome Trust Principal Fellowship (101896), European Research Council Advance Grant (323113-NETSIGNAL), European Commission FP7 ITN Extrabrain (606950 EXTRABRAIN) (D.A.R.), Russian Science Foundation grant 15-14-30000 (Fig. 3AB data; D.A.R.); German Research Foundation (DFG, SFB1089 B03, SPP1757 HE6949/1 and HE6949/3), the European Commission ITN EU-Glia, Human Frontiers Science Program, NRW Rückkehrerprogramm, UCL Excellence Bridging Award (C.H.). The authors thank Sergey Alexin and Volodymyr Hromakov (AMCBridge LLC) for inspirational help with software solutions. The authors declare no conflict of interest.

\section{REFERENCES}

1. Parpura, V., et al. Glutamate-mediated astrocyte-neuron signalling. Nature 369, 744-747 (1994).

2. Nedergaard, M. Direct signaling from astrocytes to neurons in cultures of mammalian brain cells. Science 263, 1768-1771 (1994).

3. Verkhratsky, A. \& Kettenmann, H. Calcium signalling in glial cells. Trends Neurosci 19, 346-352 (1996).

4. Araque, A., et al. Gliotransmitters travel in time and space. Neuron 81, 728-739 (2014).

5. Volterra, A., Liaudet, N. \& Savtchouk, I. Astrocyte $\mathrm{Ca}^{2+}$ signalling: an unexpected complexity. Nat Rev Neurosci 15, 327-335 (2014).

6. Bernardinelli, Y., et al. Activity-dependent structural plasticity of perisynaptic astrocytic domains promotes excitatory synapse stability. Curr Biol 24, 1679-1688 (2014).

7. Ventura, R. \& Harris, K.M. Three-dimensional relationships between hippocampal synapses and astrocytes. $J$. Neurosci. 19, 6897-6906 (1999).

8. Witcher, M.R., et al. Three-dimensional relationships between perisynaptic astroglia and human hippocampal synapses. Glia 58, 572-587 (2010).

9. Patrushev, I., Gavrilov, N., Turlapov, V. \& Semyanov, A. Subcellular location of astrocytic calcium stores favors extrasynaptic neuron-astrocyte communication. Cell Calcium 54, 343-349 (2013).

10. Medvedev, N., et al. Glia selectively approach synapses on thin dendritic spines. Philos Trans R Soc Lond B Biol Sci 369 (2014).

11. Bushong, E.A., Martone, M.E., Jones, Y.Z. \& Ellisman, M.H. Protoplasmic astrocytes in CA1 stratum radiatum occupy separate anatomical domains. J Neurosci 22, 183-192 (2002). 
bioRxiv preprint doi: https://doi.org/10.1101/336974; this version posted June 17, 2018. The copyright holder for this preprint (which was not certified by peer review) is the author/funder, who has granted bioRxiv a license to display the preprint in perpetuity. It is made available under aCC-BY-NC-ND 4.0 International license.

12. Shigetomi, E., et al. Imaging calcium microdomains within entire astrocyte territories and endfeet with GCaMPs expressed using adeno-associated viruses. J Gen Physiol 141, 633-647 (2013).

13. Hama, K., Arii, T., Katayama, E., Marton, M. \& Ellisman, M.H. Tri-dimensional morphometric analysis of astrocytic processes with high voltage electron microscopy of thick Golgi preparations. J Neurocytol 33, 277 285 (2004).

14. Rusakov, D.A. Disentangling calcium-driven astrocyte physiology. Nature Rev. Neurosci. 16, $226-233$ (2015).

15. Bazargani, N. \& Attwell, D. Astrocyte calcium signaling: the third wave. Nature Neurosci. 19, 182-189 (2016).

16. Sibille, J., Dao Duc, K., Holcman, D. \& Rouach, N. The neuroglial potassium cycle during neurotransmission: role of Kir4.1 channels. PLoS Comput Biol 11, e1004137 (2015).

17. Butt, A.M. \& Kalsi, A. Inwardly rectifying potassium channels (Kir) in central nervous system glia: a special role for Kir4.1 in glial functions. J Cell Mol Med 10, 33-44 (2006).

18. Ransom, B.R. \& Carlini, W.G. Electrophysiological properties fo astrocytes. in Astrocytes: Biochemistry, physiology, and pharmacology of astrocytes (ed. S. Fedoroff \& A. Vernadakis) 1-50 (Academic Press, London, 1986).

19. Kofuji, P. \& Newman, E.A. Potassium buffering in the central nervous system. Neurosci. 129, $1045-1056$ (2004).

20. Orkand, R.K., Nicholls, J.G. \& Kuffler, S.W. Effect of nerve impulses on the membrane potential of glial cells in the central nervous system of amphibia. J Neurophysiol 29, 788-806 (1966).

21. Billups, B., et al. Physiological and pathological operation of glutamate transporters. Prog. Brain Res. 116, $45-$ 57 (1998).

22. Nagelhus, E.A. \& Ottersen, O.P. Physiological roles of aquaporin-4 in brain. Physiol Rev 93, 1543-1562 (2013).

23. Kirischuk, S., Parpura, V. \& Verkhratsky, A. Sodium dynamics: another key to astroglial excitability? Trends Neurosci 35, 497-506 (2012).

24. Hines, M.L. \& Carnevale, N.T. NEURON: a tool for neuroscientists. Neuroscientist 7, 123-135 (2001).

25. Hines, M.L., Morse, T., Migliore, M., Carnevale, N.T. \& Shepherd, G.M. ModelDB: A Database to Support Computational Neuroscience. J Comput Neurosci 17, 7-11 (2004).

26. Manninen, T., Havela, R. \& Linne, M.L. Reproducibility and Comparability of Computational Models for Astrocyte Calcium Excitability. Front Neuroinform 11, 11 (2017).

27. Oschmann, F., Berry, H., Obermayer, K. \& Lenk, K. From in silico astrocyte cell models to neuron-astrocyte network models: A review. Brain research bulletin 136, 76-84 (2018).

28. De Pitta, M., Goldberg, M., Volman, V., Berry, H. \& Ben-Jacob, E. Glutamate regulation of calcium and IP3 oscillating and pulsating dynamics in astrocytes. J Biol Phys 35, 383-411 (2009).

29. Hofer, T., Venance, L. \& Giaume, C. Control and plasticity of intercellular calcium waves in astrocytes: A modeling approach. J. Neurosci. 22, 4850-4859 (2002).

30. Cao, P.X., Donovan, G., Falcke, M. \& Sneyd, J. A Stochastic Model of Calcium Puffs Based on SingleChannel Data. Biophys J 105, 1133-1142 (2013).

31. Nadkarni, S. \& Jung, P. Modeling synaptic transmission of the tripartite synapse. Phys Biol 4, 1-9 (2007).

32. Rusakov, D.A. The role of perisynaptic glial sheaths in glutamate spillover and extracellular $\mathrm{Ca}^{2+}$ depletion. Biophys J 81, 1947-1959 (2001).

33. De Pitta, M., Volman, V., Berry, H. \& Ben-Jacob, E. A tale of two stories: astrocyte regulation of synaptic depression and facilitation. PLoS Comput Biol 7, e1002293 (2011).

34. Wallach, G., et al. Glutamate Mediated Astrocytic Filtering of Neuronal Activity. PLoS Computational Biology 10 (2014).

35. Nadkarni, S. \& Jung, P. Spontaneous oscillations of dressed neurons: A new mechanism for epilepsy? Physical Review Letters 91 (2003).

36. Savtchenko, L.P. \& Rusakov, D.A. Regulation of rhythm genesis by volume-limited, astroglia-like signals in neural networks. Philos Trans R Soc Lond B Biol Sci 369 (2014).

37. Henneberger, C., Papouin, T., Oliet, S.H. \& Rusakov, D.A. Long-term potentiation depends on release of Dserine from astrocytes. Nature 463, 232-236 (2010).

38. Di Castro, M.A., et al. Local Ca2+ detection and modulation of synaptic release by astrocytes. Nature Neurosci. 14, 1276-1284 (2011). 
bioRxiv preprint doi: https://doi.org/10.1101/336974; this version posted June 17, 2018. The copyright holder for this preprint (which was not certified by peer review) is the author/funder, who has granted bioRxiv a license to display the preprint in perpetuity. It is made available under aCC-BY-NC-ND 4.0 International license.

39. Panatier, A., et al. Astrocytes are endogenous regulators of basal transmission at central synapses. Cell 146, 785-798 (2011).

40. Pannasch, U. \& Rouach, N. Emerging role for astroglial networks in information processing: from synapse to behavior. Trends Neurosci 36, 405-417 (2013).

41. Hama, K., Arii, T., Katayama, E., Marton, M. \& Ellisman, M.H. Tri-dimensional morphometric analysis of astrocytic processes with high voltage electron microscopy of thick Golgi preparations. Journal of neurocytology 33, 277-285 (2004)

42. Reeves, A.M., Shigetomi, E. \& Khakh, B.S. Bulk loading of calcium indicator dyes to study astrocyte physiology: key limitations and improvements using morphological maps. J Neurosci 31, 9353-9358 (2011).

43. Viola, G.G., et al. Morphological changes in hippocampal astrocytes induced by environmental enrichment in mice. Brain Res. 1274, 47-54 (2009).

44. Sachs, F. Practical Limits on the Maximal Speed of Solution Exchange for Patch Clamp Experiments. Biophys J 77, 682-690 (1999).

45. Dunn, K.M., Hill-Eubanks, D.C., Liedtke, W.B. \& Nelson, M.T. TRPV4 channels stimulate Ca2+-induced $\mathrm{Ca} 2+$ release in astrocytic endfeet and amplify neurovascular coupling responses. Proc Natl Acad Sci U S A 110, 6157-6162 (2013).

46. Newman, E.A., Frambach, D.A. \& Odette, L.L. Control of extracellular potassium levels by retinal glial cell K+ siphoning. Science 225, 1174-1175 (1984).

47. Bazargani, N. \& Attwell, D. Amines, Astrocytes, and Arousal. Neuron 94, 228-231 (2017).

48. Rodriguez, J.J., et al. Long-term potentiation in the rat dentate gyrus is associated with enhanced Arc/Arg3.1 protein expression in spines, dendrites and glia. Eur J Neurosci 21, 2384-2396 (2005).

49. Korogod, N., Petersen, C.C.H. \& Knott, G.W. Ultrastructural analysis of adult mouse neocortex comparing aldehyde perfusion with cryo fixation. Elife 4 (2015).

50. Rusakov, D.A., Harrison, E. \& Stewart, M.G. Synapses in hippocampus occupy only 1-2\% of cell membranes and are spaced less than half-micron apart: a quantitative ultrastructural analysis with discussion of physiological implications. Neuropharmacol. 37, 513-521 (1998).

51. Rusakov, D.A., Kullmann, D.M. \& Stewart, M.G. Hippocampal synapses: do they talk to their neighbours? Trends Neurosci 22, 382-388 (1999).

52. Savtchenko, L.P., Sylantyev, S. \& Rusakov, D.A. Central synapses release a resource-efficient amount of glutamate. Nat Neurosci 16, 10-12 (2013).

53. Sylantyev, S., et al. Electric fields due to synaptic currents sharpen excitatory transmission. Science 319, 18451849 (2008).

54. Savtchenko, L.P. \& Rusakov, D.A. The optimal height of the synaptic cleft. Proc Natl Acad Sci U S A 104, 1823-1828 (2007).

55. Lehre, K.P. \& Rusakov, D.A. Asymmetry of glia near central synapses favors presynaptically directed glutamate escape. Biophys J 83, 125-134 (2002).

56. Ogata, K. \& Kosaka, T. Structural and quantitative analysis of astrocytes in the mouse hippocampus. Neurosci. 113, 221-233 (2002).

57. Chvatal, A., Anderova, M. \& Kirchhoff, F. Three-dimensional confocal morphometry - a new approach for studying dynamic changes in cell morphology in brain slices. Journal of anatomy 210, 671-683 (2007).

58. Chounlamountry, K. \& Kessler, J.P. The ultrastructure of perisynaptic glia in the nucleus tractus solitarii of the adult rat: Comparison between single synapses and multisynaptic arrangements. Glia 59, 655-663 (2011).

59. Reits, E.A. \& Neefjes, J.J. From fixed to FRAP: measuring protein mobility and activity in living cells. Nat Cell Biol 3, E145-147 (2001).

60. Svoboda, K., Tank, D.W. \& Denk, W. Direct measurement of coupling between dendritic spines and shafts. Science 272, 716-719 (1996).

61. Anders, S., et al. Spatial properties of astrocyte gap junction coupling in the rat hippocampus. Philos Trans $R$ Soc Lond B Biol Sci 369, 20130600 (2014).

62. Golowasch, J., et al. Membrane Capacitance Measurements Revisited: Dependence of Capacitance Value on Measurement Method in Nonisopotential Neurons. J. Neurophysiol. 102, 2161-2175 (2009).

63. Scott, R., Ruiz, A., Henneberger, C., Kullmann, D.M. \& Rusakov, D.A. Analog modulation of mossy fiber transmission is uncoupled from changes in presynaptic Ca2+. J. Neurosci. 28, 7765-7773 (2008).

64. Seifert, G., et al. Analysis of astroglial $\mathrm{K}+$ channel expression in the developing hippocampus reveals a predominant role of the Kir4.1 subunit. J Neurosci 29, 7474-7488 (2009). 
bioRxiv preprint doi: https://doi.org/10.1101/336974; this version posted June 17, 2018. The copyright holder for this preprint (which was not certified by peer review) is the author/funder, who has granted bioRxiv a license to display the preprint in perpetuity. It is made available under aCC-BY-NC-ND 4.0 International license.

65. Djukic, B., Casper, K.B., Philpot, B.D., Chin, L.S. \& McCarthy, K.D. Conditional knock-out of Kir4.1 leads to glial membrane depolarization, inhibition of potassium and glutamate uptake, and enhanced short-term synaptic potentiation. J Neurosci 27, 11354-11365 (2007).

66. Zhang, Z., et al. Transport direction determines the kinetics of substrate transport by the glutamate transporter EAAC1. Proc Natl Acad Sci U S A 104, 18025-18030 (2007).

67. Bergles, D.E. \& Jahr, C.E. Synaptic activation of glutamate transporters in hippocampal astrocytes. Neuron 19, 1297-1308 (1997).

68. Lehre, K.P. \& Danbolt, N.C. The number of glutamate transporter subtype molecules at glutamatergic synapses: Chemical and stereological quantification in young adult rat brain. J. Neurosci. 18, 8751-8757 (1998).

69. Sibille, J., Pannasch, U. \& Rouach, N. Astroglial potassium clearance contributes to short-term plasticity of synaptically evoked currents at the tripartite synapse. J Physiol 592, 87-102 (2014).

70. Gardner-Medwin, A.R. \& Nicholson, C. Changes of Extracellular Potassium Activity Induced by ElectricCurrent through Brain-Tissue in the Rat. J. Physiol. 335, 375-392 (1983).

71. Chen, K.C. \& Nicholson, C. Spatial buffering of potassium ions in brain extracellular space. Biophys J 78, 2776-2797 (2000).

72. McBain, C.J., Traynelis, S.F. \& Dingledine, R. Regional variation of extracellular space in the hippocampus. Science 249, 674-677 (1990).

73. Giaume, C., Koulakoff, A., Roux, L., Holcman, D. \& Rouach, N. Astroglial networks: a step further in neuroglial and gliovascular interactions. Nat Rev Neurosci 11, 87-99 (2010).

74. MacVicar, B.A. \& Thompson, R.J. Non-junction functions of pannexin-1 channels. Trends Neurosci 33, 93102 (2010).

75. Wallraff, A., et al. The impact of astrocytic gap junctional coupling on potassium buffering in the hippocampus. J Neurosci 26, 5438-5447 (2006).

76. Pannasch, U., et al. Connexin 30 sets synaptic strength by controlling astroglial synapse invasion. Nat Neurosci 17, 549-558 (2014).

77. Nedergaard, M., Rodriguez, J.J. \& Verkhratsky, A. Glial calcium and diseases of the nervous system. Cell Calcium 47, 140-149 (2010).

78. Berridge, M.J. \& Taylor, C.W. Inositol trisphosphate and calcium signaling. Cold Spring Harb Symp Quant Biol 53 Pt 2, 927-933 (1988).

79. De Young, G.W. \& Keizer, J. A single-pool inositol 1,4,5-trisphosphate-receptor-based model for agoniststimulated oscillations in Ca2+ concentration. Proc Natl Acad Sci U S A 89, 9895-9899 (1992).

80. Berridge, M.J. Calcium microdomains: organization and function. Cell Calcium 40, 405-412 (2006).

81. Ross, W.N. Understanding calcium waves and sparks in central neurons. Nature Rev. Neurosci. 13, 157-168 (2012).

82. Haustein, M.D., et al. Conditions and constraints for astrocyte calcium signaling in the hippocampal mossy fiber pathway. Neuron 82, 413-429 (2014).

83. Rungta, R.L., et al. Ca2+ Transients in Astrocyte Fine Processes Occur Via Ca2+ Influx in the Adult Mouse Hippocampus. Glia 64, 2093-2103 (2016).

84. Agarwal, A., et al. Transient Opening of the Mitochondrial Permeability Transition Pore Induces Microdomain Calcium Transients in Astrocyte Processes. Neuron 93, 587-605 e587 (2017).

85. Wang, Z., Tymianski, M., Jones, O.T. \& Nedergaard, M. Impact of cytoplasmic calcium buffering on the spatial and temporal characteristics of intercellular calcium signals in astrocytes. J Neurosci 17, 7359-7371 (1997).

86. Sabatini, B.L., Oertner, T.G. \& Svoboda, K. The life cycle of Ca2+ ions in dendritic spines. Neuron 33, 439 (2002).

87. Fink, C.C., et al. An image-based model of calcium waves in differentiated neuroblastoma cells. Biophys J 79, 163-183 (2000).

88. Hofer, T., Venance, L. \& Giaume, C. Control and plasticity of intercellular calcium waves in astrocytes: a modeling approach. J Neurosci 22, 4850-4859 (2002).

89. Ullah, G., Jung, P. \& Cornell-Bell, A.H. Anti-phase calcium oscillations in astrocytes via inositol $(1,4,5)-$ trisphosphate regeneration. Cell Calcium 39, 197-208 (2006).

90. Schaff, J., Fink, C.C., Slepchenko, B., Carson, J.H. \& Loew, L.M. A general computational framework for modeling cellular structure and function. Biophys J 73, 1135-1146 (1997). 
bioRxiv preprint doi: https://doi.org/10.1101/336974; this version posted June 17, 2018. The copyright holder for this preprint (which was not certified by peer review) is the author/funder, who has granted bioRxiv a license to display the preprint in perpetuity. It is made available under aCC-BY-NC-ND 4.0 International license.

91. Zheng, K., et al. Time-resolved imaging reveals heterogeneous landscapes of nanomolar $\mathrm{Ca}^{2+}$ in neurons and astroglia. Neuron 88, 277-288 (2015).

92. Ding, F., et al. alpha1-Adrenergic receptors mediate coordinated $\mathrm{Ca} 2+$ signaling of cortical astrocytes in awake, behaving mice. Cell Calcium 54, 387-394 (2013).

93. Grosche, A., et al. Versatile and simple approach to determine astrocyte territories in mouse neocortex and hippocampus. PLoS One 8, e69143 (2013).

94. Chen, T.W., et al. Ultrasensitive fluorescent proteins for imaging neuronal activity. Nature 499, 295-300 (2013).

95. Haider, B., Hausser, M. \& Carandini, M. Inhibition dominates sensory responses in the awake cortex. Nature 493, 97-+ (2013).

96. Srinivasan, R., et al. $\mathrm{Ca}(2+)$ signaling in astrocytes from Ip3r2(-/-) mice in brain slices and during startle responses in vivo. Nat Neurosci 18, 708-717 (2015).

97. Scemes, E. \& Giaume, C. Astrocyte calcium waves: What they are and what they do. Glia 54, 716-725 (2006).

98. Rusakov, D.A., Bard, L., Stewart, M.G. \& Henneberger, C. Diversity of astroglial functions alludes to subcellular specialisation. Trends Neurosci 37, 228-242 (2014).

99. Khakh, B.S. \& Sofroniew, M.V. Diversity of astrocyte functions and phenotypes in neural circuits. Nat Neurosci 18, 942-952 (2015).

100. Rusakov, D.A., Zheng, K. \& Henneberger, C. Astrocytes as regulators of synaptic function: a quest for the Ca2+ master key. Neuroscientist 17, 513-523 (2011).

101. Schneggenburger, R. \& Neher, E. Presynaptic calcium and control of vesicle fusion. Curr Opin Neurobiol 15, 266-274 (2005).

102. Eggermann, E., Bucurenciu, I., Goswami, S.P. \& Jonas, P. Nanodomain coupling between Ca(2)(+) channels and sensors of exocytosis at fast mammalian synapses. Nat Rev Neurosci 13, 7-21 (2012).

103. Shigetomi, E., Tong, X., Kwan, K.Y., Corey, D.P. \& Khakh, B.S. TRPA1 channels regulate astrocyte resting calcium and inhibitory synapse efficacy through GAT-3. Nat Neurosci 15, 70-80 (2012).

104. Skupin, A. \& Falcke, M. From puffs to global Ca2+ signals: How molecular properties shape global signals. Chaos 19 (2009).

105. Thurley, K. \& Falcke, M. Derivation of Ca2+ signals from puff properties reveals that pathway function is robust against cell variability but sensitive for control. Proc. Natl. Acad. Sci. USA 108, 427-432 (2011).

106. Smith, I.F., Wiltgen, S.M., Shuai, J.W. \& Parker, I. Ca2+ Puffs Originate from Preestablished Stable Clusters of Inositol Trisphosphate Receptors. Science Signaling 2 (2009).

107. Thurley, K., et al. Timescales of IP3-Evoked Ca2+ Spikes Emerge from Ca2+ Puffs Only at the Cellular Level. Biophys J 101, 2638-2644 (2011).

108. TaufiqUrRahman, Skupin, A., Falcke, M. \& Taylor, C.W. Clustering of InsP(3) receptors by InsP(3) retunes their regulation by InsP(3) and Ca2+. Nature 458, 655-659 (2009).

109. Chen, Y., et al. Suppressing effect of $\mathrm{Ca} 2+$ blips on puff amplitudes by inhibiting channels to prevent recovery. Physical Review E 94 (2016).

110. Zheng, K.Y., et al. Nanoscale diffusion in the synaptic cleft and beyond measured with time-resolved fluorescence anisotropy imaging. Scientific Reports 7, 42022 (2017).

111. Popov, V., Medvedev, N.I., Davies, H.A. \& Stewart, M.G. Mitochondria form a filamentous reticular network in hippocampal dendrites but are present as discrete bodies in axons: a three-dimensional ultrastructural study. J Comp Neurol 492, 50-65 (2005).

112. Medvedev, N.I., et al. The N-methyl-D-aspartate receptor antagonist CPP alters synapse and spine structure and impairs long-term potentiation and long-term depression induced morphological plasticity in dentate gyrus of the awake rat. Neurosci. 165, 1170-1181 (2010).

113. Bergles, D.E., Tzingounis, A.V. \& Jahr, C.E. Comparison of coupled and uncoupled currents during glutamate uptake by GLT-1 transporters. J Neurosci 22, 10153-10162 (2002).

114. Hernjak, N., et al. Modeling and analysis of calcium signaling events leading to long-term depression in cerebellar Purkinje cells. Biophys J 89, 3790-3806 (2005).

115. Zheng, K., Scimemi, A. \& Rusakov, D.A. Receptor actions of synaptically released glutamate: the role of transporters on the scale from nanometers to microns. Biophys J 95, 4584-4596 (2008). 
bioRxiv preprint doi: https:/doi.org/10 1101/336974; this version posted June 17,2018 . The copyright holder for this preprint (which was not certified by peer review) is the author/funder, who has granted bioRxiv a license to display the preprint in perpetuity. It is made available under aCC-BY-NC-ND 4.0 International license.

a

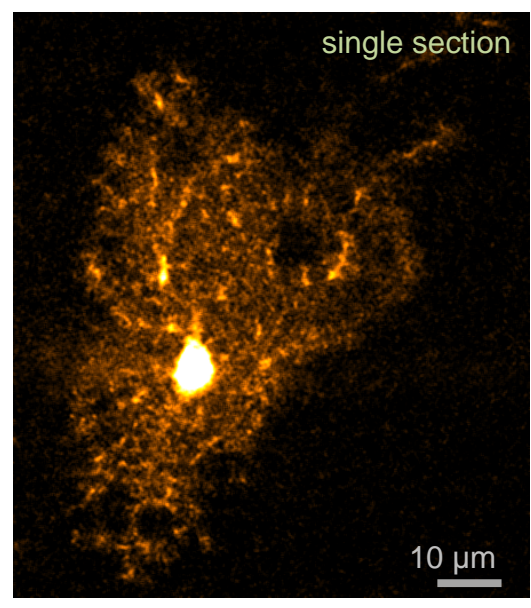

b

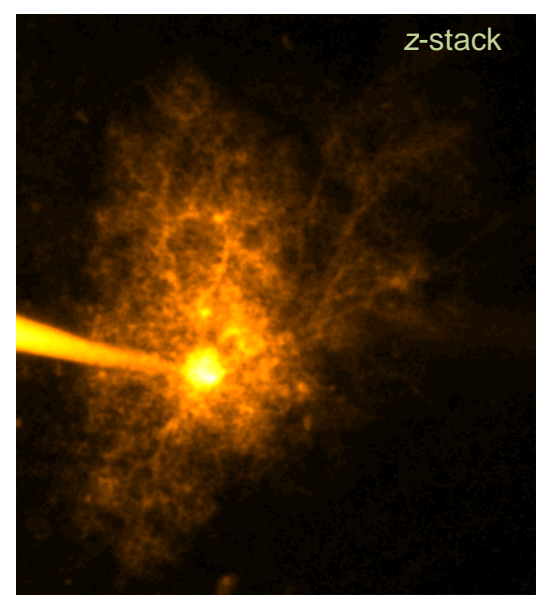

C

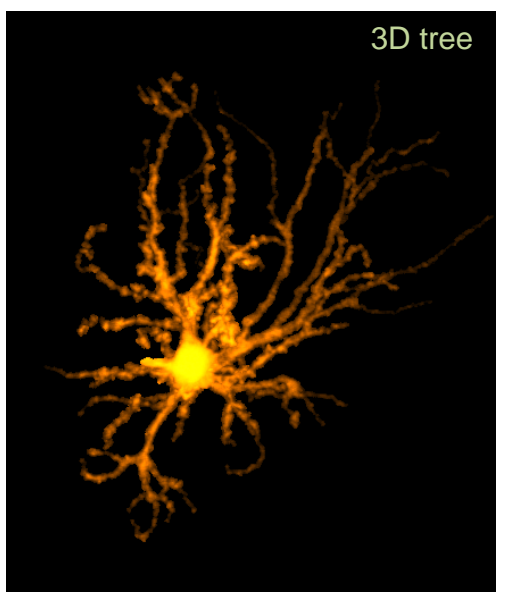

d

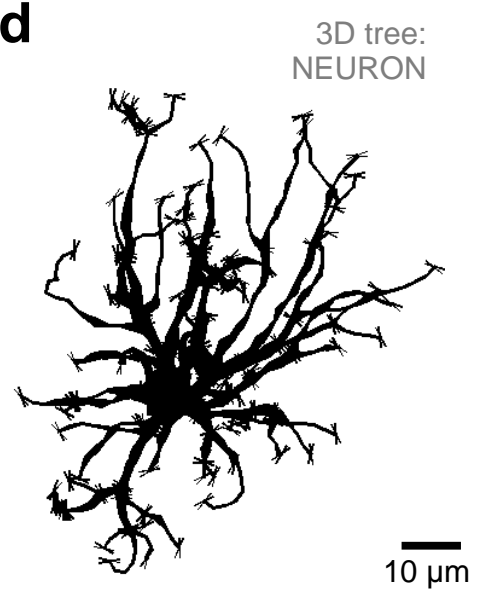

e

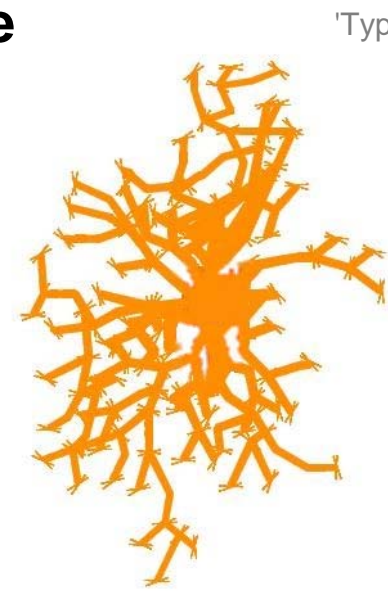

'Typical' 3D tree

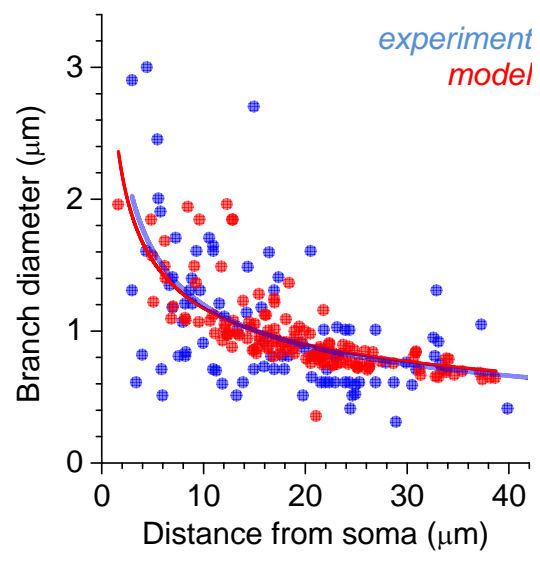

Figure 1. Reconstructing astroglial stem tree in silico.

a, A characteristic image of CA1 astroglia, whole-cell load with Alexa Fluor $594\left(\lambda_{x}{ }^{2 p}=800\right.$ $\mathrm{nm}$ ), single optical section (stratum radiatum, depth of $\sim 100 \mu \mathrm{m}$ ).

b, Cell as in panel a shown as a full z-stack projection.

c, Stem tree of astroglia shown in a-b, separated and reconstructed in 3D using NeuroTrace (Fiji ImageJ, NIH); 2D view of a 3D image.

d, Astrocyte stem tree shown in panel c quantified, loaded and displayed in NEURON format using Vaa3D (Allen Institute); thin 'buds' indicate initial seeds for 'planting, nanoscopic protrusions at a certain longitudinal density; 2D view.

e, Diagram, 'typical' astrocyte stem tree built by modifying a library neurogliaform cell (2D view); plot, matching the branch diameters in the model (red) and in recorded astroglia (blue; $\mathrm{n}$ $=13$ cells including 98 dendrites); solid lines, the best-fit dependence (power low, $y=a \cdot x^{b}$ ) for the corresponding data scatters. 
a

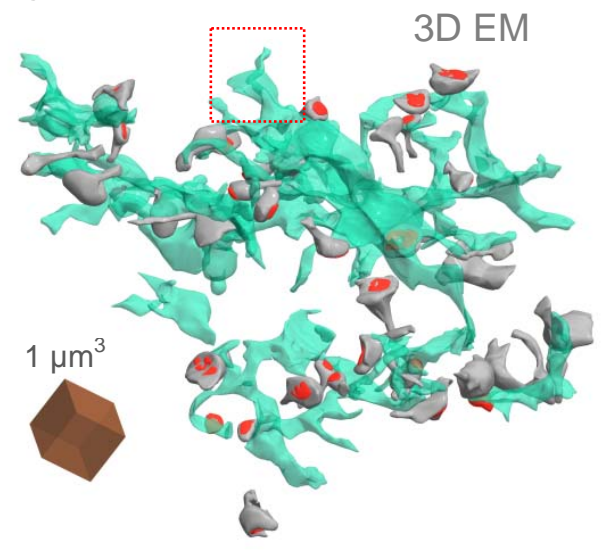

d
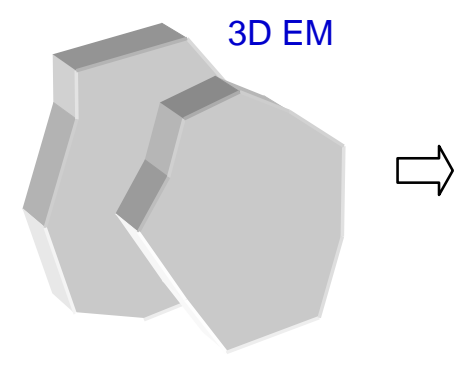

e

3D EM
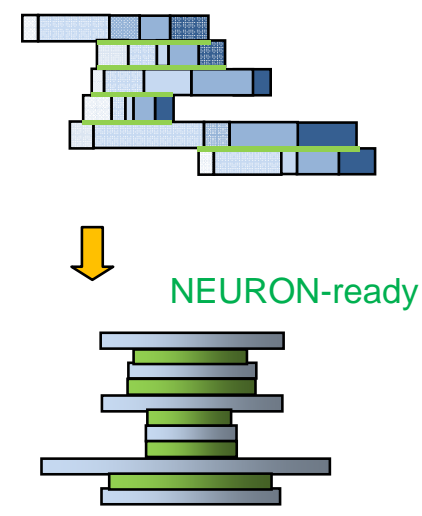

b 3D EM in silico

C
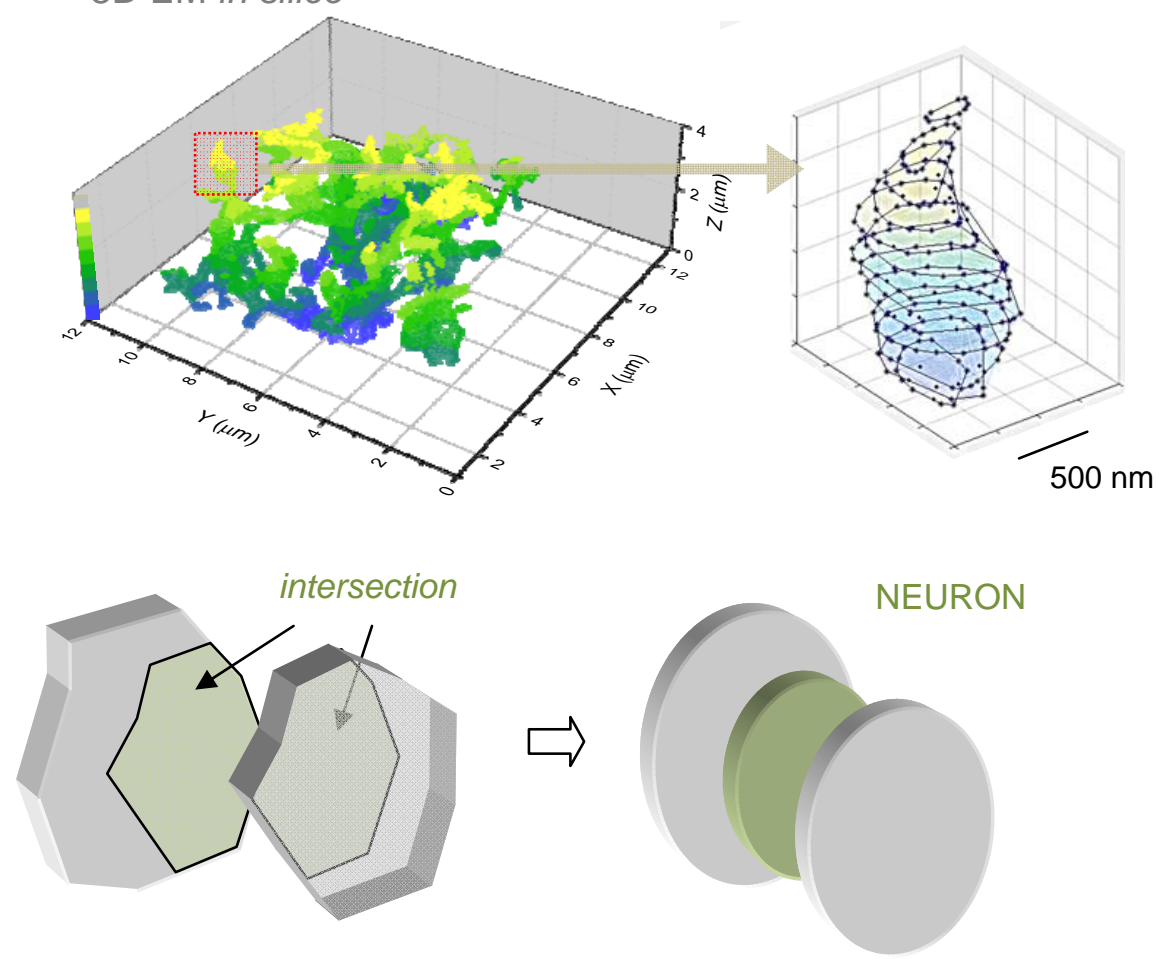

g

3D EM
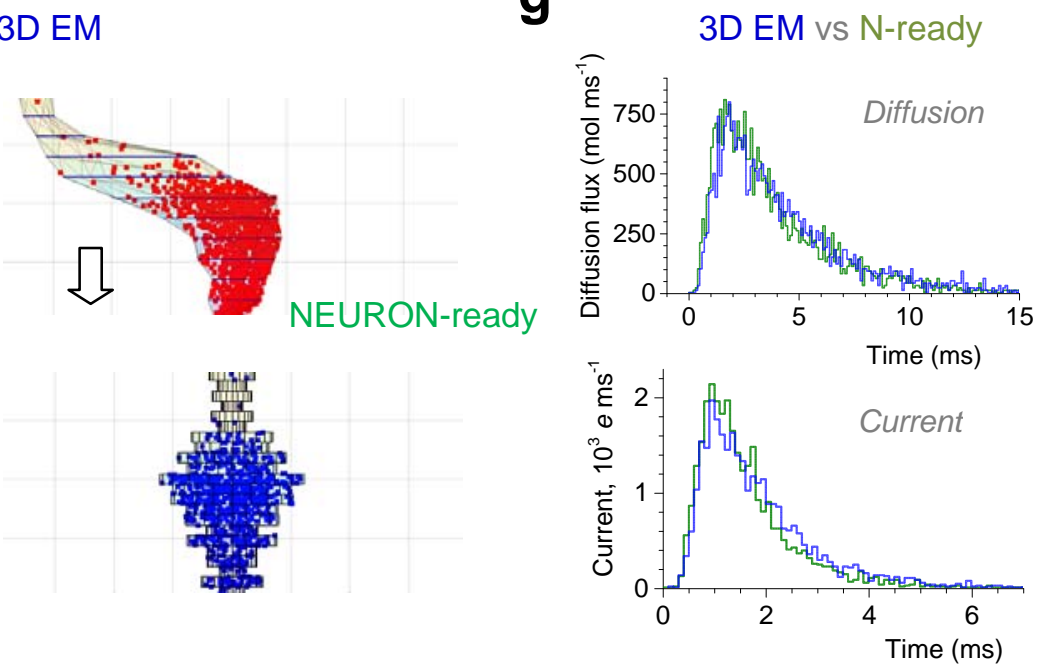

Figure 2. Documenting and reconstructing in silico nanoscopic astroglial protrusions.

a, 3D EM reconstruction of an astrocytic fragment (green) and adjacent dendritic spines (grey) with postsynaptic densities (red), from serial sections in area CA1; surface rendering applied for clarity, as in ${ }^{10}$; dotted square, fragment of interest.

b, Fragment shown in a but with the surface point scatter delimiting the shape; false colour scale, z-depth as indicated; dotted square, fragment of interest (nanoscopic astroglial process) as in $\mathbf{a}$. 
bioRxiv preprint doi: https://doi.org/10.1101/336974; this version posted June 17 2018. The copyright holder for this preprint (which was not certified by peer review) is the author/funder, who has granted bioRxiv a license to display the preprint in perpetuity. It is made available under aCC-BY-NC-ND 4.0 International license.

c, Astroglial process highlighted in a-b shown as a stack of serial polygonal sections (60 nm thick, to follow EM serial sections) delimited by the surface points.

d, Transformation of the adjacent EM sections (left; grey polygonal slabs with base areas $S_{i}$ and $S_{i+1}$ ) with intersection area $T_{i}$ (middle; green polygons) into NEURON-compatible two main (grey, 'leaves') and one transitional (green, 'stalk') cylindrical slabs with the corresponding base areas (right).

e, Transformation of the 3D EM reconstructed process fragment (top panel) into NEURONcompatible cylinder section stacks (bottom panel); side view. Individual sections (blue, top) were transformed into 'main' cylinders of the same base area (blue, bottom). Green segments (top) depict adjacent surfaces between sections, which are represented by green 'transitional' cylinders (bottom), as detailed in $\mathbf{d}$.

f, A characteristic example of a 3D-EM reconstructed astroglial process represented by serial polygonal sections (top) and its representation by serial cylindrical compartments (bottom). Scattered dots illustrate a snapshot of the Monte Carlo simulation test (monitored live in ASTRO; Supplementary Movie 1) in which Brownian particles are injected into the bottom of the 3D structure, and their arrival time at the top is registered, to compare molecular diffusivity (no electric field) and electrodynamic properties $\left(2.5 \cdot 10^{3} \mathrm{~V} / \mathrm{m}\right.$ electric field in the $\mathrm{z}$-direction, one electron charge $e=1.6 \cdot 10^{-19} \mathrm{C}$ per particle applied) between the two shapes.

$\mathbf{g}$, The outcome of Monte Carlo tests for the two shapes shown in $\mathbf{e}$, for the molecular diffusion flux (top) and ion current (bottom), measured at the top exit of the shapes (as in e), upon injection of the Brownian particles into the bottom entry (as in e); blue and green, 3D-EMreconstructed and NEURON-compatible shapes, respectively. See ${ }^{53}$ regarding details of electrodiffusion simulations. 
bioRxiv preprint doi: https//doi org/10 1101/336974; this version posted June 17,2018 . The copyright holder for this preprint (which was

a

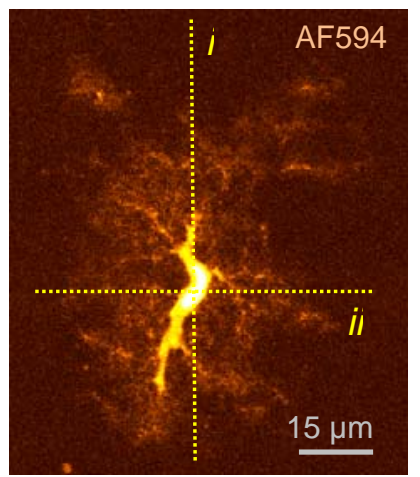

C

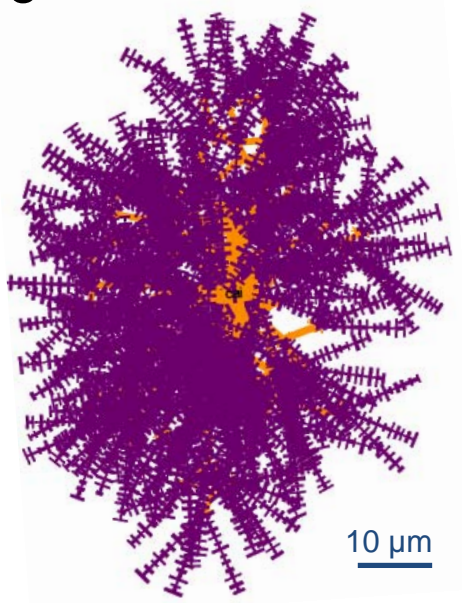

f

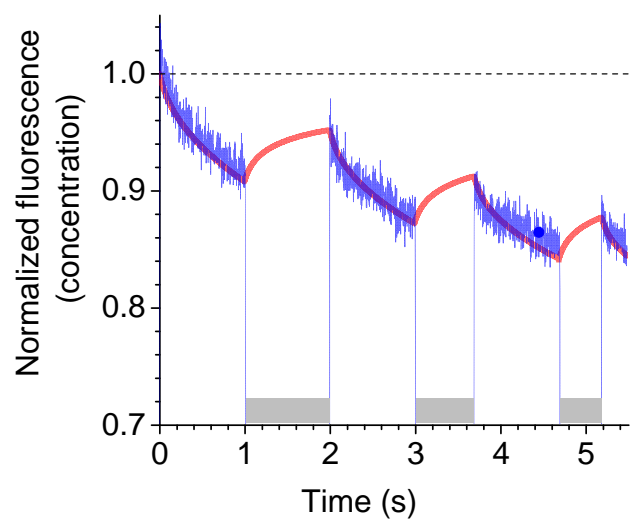

b
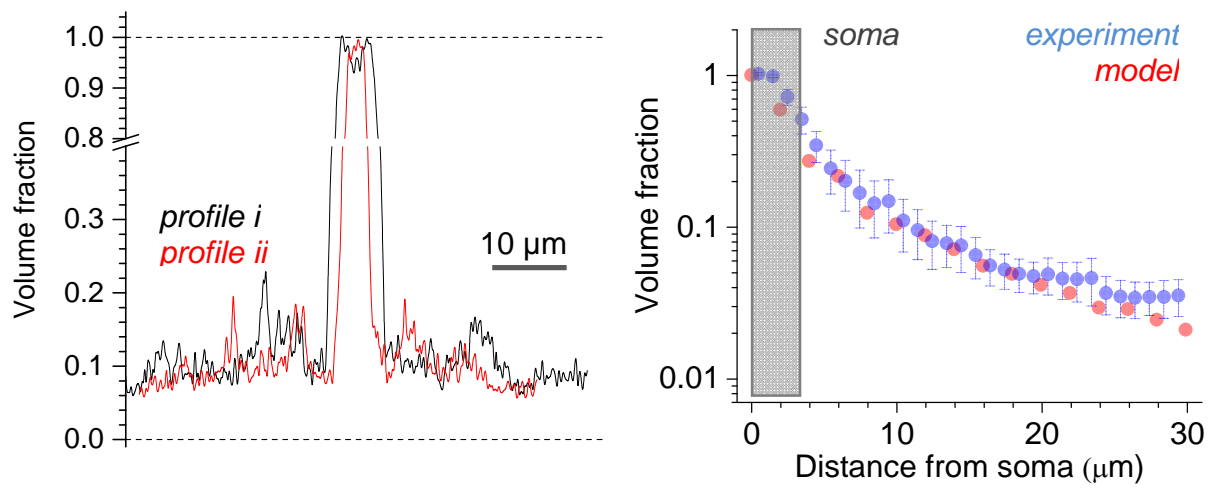

e

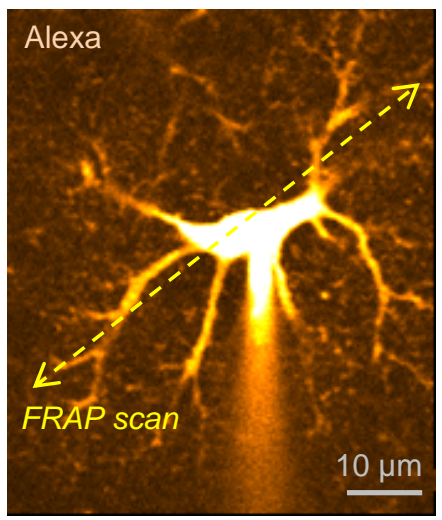

FRAP scan

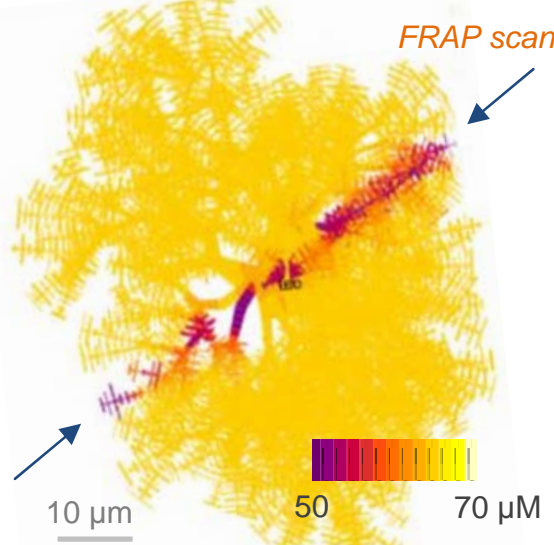

g

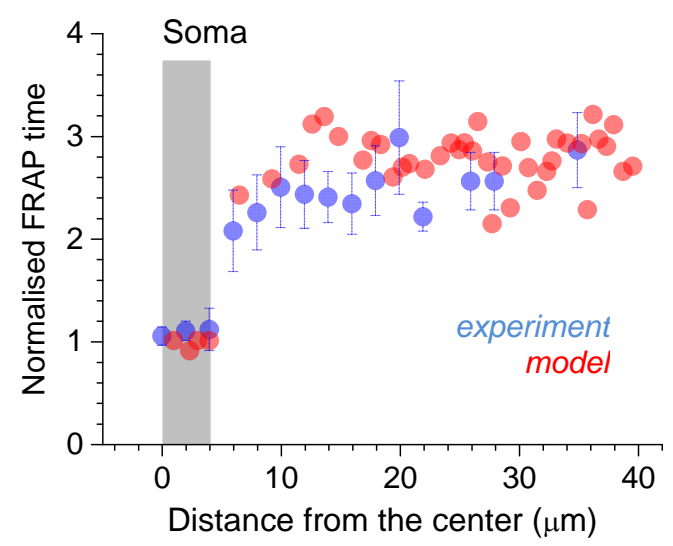

Figure 3. NEURON-based astrocyte model: determining volumetric quantities.

a, Image panel, a characteristic astrocyte in area CA1 (Alexa Fluor 594, $\lambda_{\mathrm{x}}{ }^{2 \mathrm{p}}=800 \mathrm{~nm}$ ) seen in a single $2 \mathrm{PE}$ optical section $(\sim 1 \mu \mathrm{m}$ thick) crossing the cell soma; dotted lines, sampling fluorescence intensity profiles reporting the astrocyte tissue volume fraction (VF). Graph, VF profiles (fluorescence local/soma ratio) obtained along the dotted lines $i$ and $i i$ in the image, as indicated. 
bioRxiv preprint doi: https://doi.org/101101/336974; this version posted June 17, 2018. The copyright holder for this preprint (which was not certified by peer review) is the author/funder, who has granted bioRxiv a license to display the preprint in perpetuity. It is made available under aCC-BY-NC-ND 4.0 International license.

b, Matching modelled (red) and experimental (blue; data from $\mathrm{n}=13$ astrocytes) VF values (ordinate) sampled at different distances from the soma (abscissa).

c, A complete NEURON-generated astrocyte model (z-projection), with main branches depicted in orange (partly obscured by smaller processes) and nanoscopic protrusions (schematic depiction) in purple. Note that tortuous processes of real-life astroglia are represented by biophysically equivalent 'straightened' processes in the model.

d, An example of astroglia as in a; dotted line, line scan position to measure internal diffusion connectivity (using Alexa Fluor 594 photobleaching); patch pipette is seen.

e, A snapshot of a photobleaching experiment in silico showing the intracellular Alexa concentration dynamics in a modelled astrocyte; arrows, photobleaching line positioning; false colour scale, intracellular Alexa concentration, as indicated (Supplementary Movie 2).

f, Matching the modelled (red) and the experimental (blue) time course of intracellular Alexa Flour fluorescence during a photobleaching experiment as shown in d-e, one-cell example (CA1 area, stratum radiatum astrocyte). Grey segments indicate laser shutter-on when fluorescence recovery occurs (red).

g, Statistical summary of photobleaching experiments ( $\mathrm{n}=10$ astrocytes) and related simulations, as depicted in d-e, comparing experimental (blue) and simulated (red) data. 
a

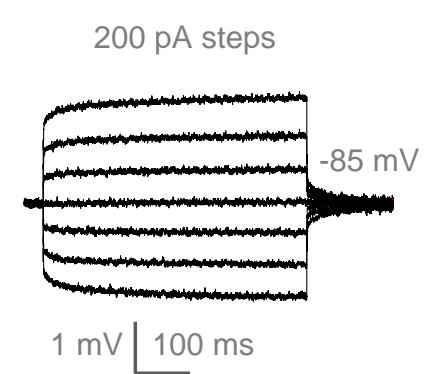

b

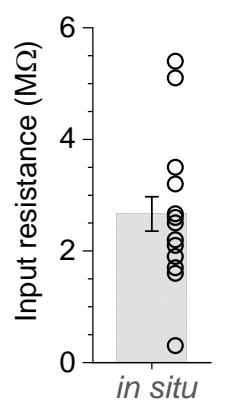

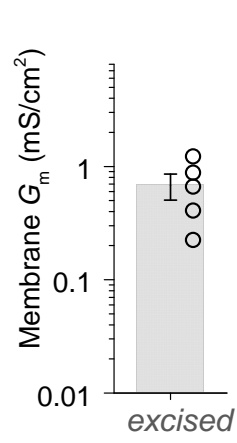

C

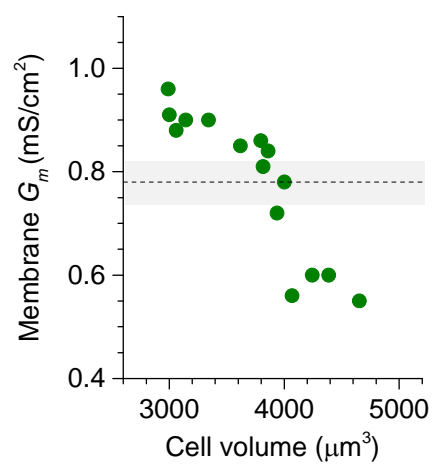

d
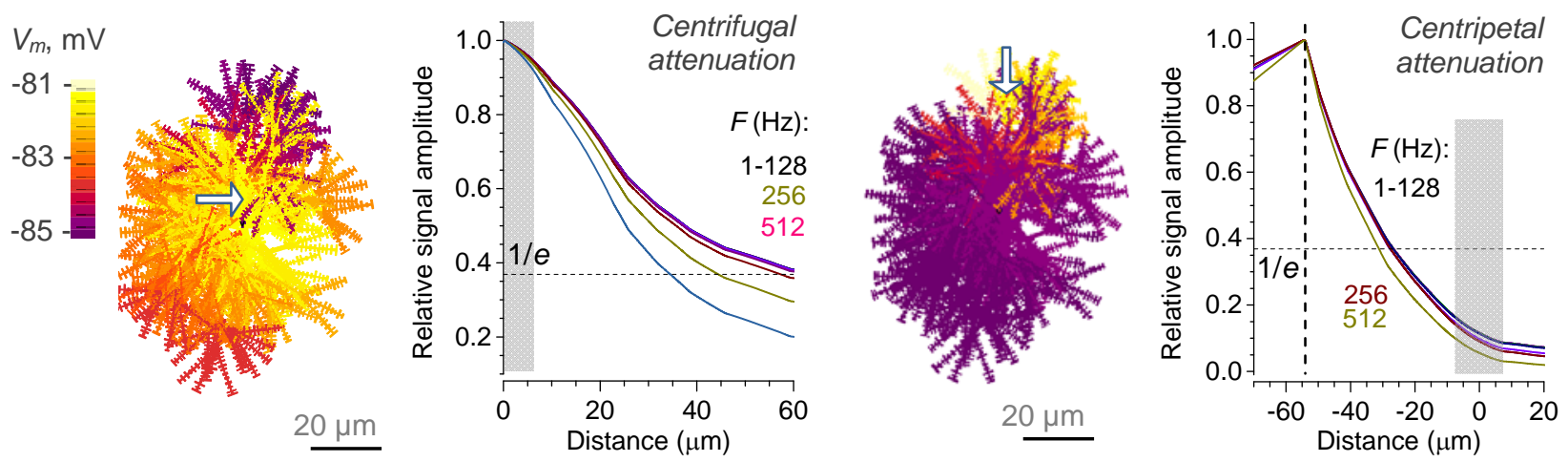

e

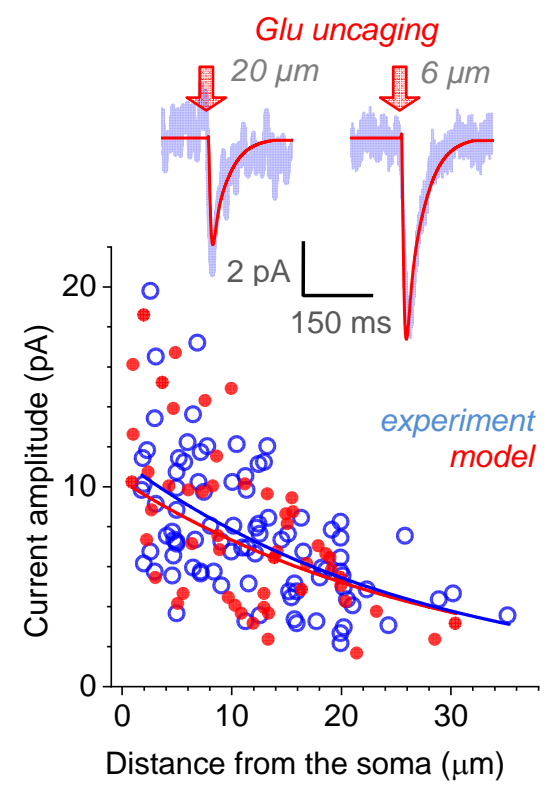

f
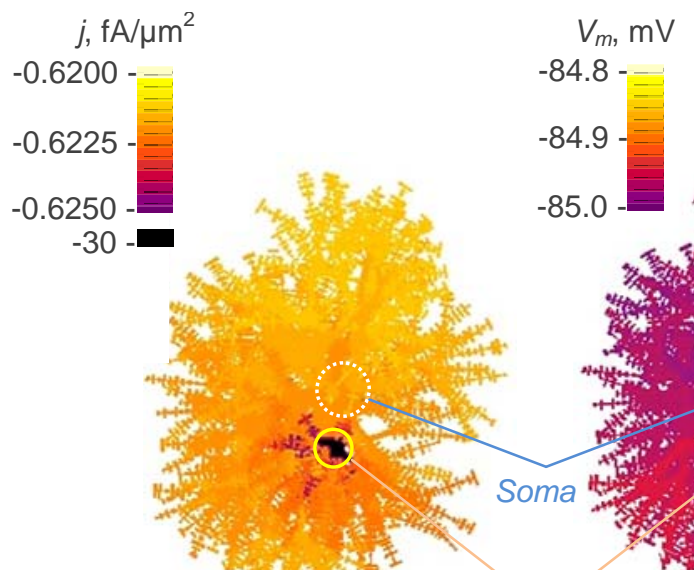

Glu uncaging

$10 \mu \mathrm{m}$

\section{Figure 4. Electrogenic properties of protoplasmic astroglia.}

a, Traces, a characteristic current-voltage recording of CA1 astroglia; graph, input resistance (bar, mean \pm SEM; dots, individual cell data; $\mathrm{n}=15$ ). 
bioRxiv preprint doi: https://doi.org/10.1101/336974; this version posted June 17, 2018. The copyright holder for this preprint (which was not certified by peer review) is the author/funder, who has granted bioRxiv a license to display the preprint in perpetuity. It is made available under aCC-BY-NC-ND 4.0 International license.

b, Specific membrane conductance $G_{\mathrm{m}}$ measured in excised whole-cell (outside-out) patches of CA1 astrocytes (bar, mean $\pm S E M$; dots, individual cell data; $n=5$ ).

c, Dots, $G_{\mathrm{m}}$ values obtained by stochastically generating astrocyte models within the empirical range of cell volumes (abscissa) and input resistance matching data shown in a; dotted line and grey shade, mean \pm SEM for the sample shown; note that NEURON-model astrocyte surface area accounts for both sides and bases of individual cylindrical compartments (Methods).

d, Membrane space constant estimated using a full astrocyte model for centrifugal (left panels) and centripetal (right panels) voltage signal propagation. Cell shape diagrams: $V_{\mathrm{m}}$ landscape snapshots generated by local application (shown by arrow) of a sine voltage signal (amplitude +5 $\mathrm{mV}$ ). Graphs: signal amplitude attenuation at various signal frequencies, as indicated, for centrifugal and centripetal cases, as indicated.

e, Traces, example of whole-cell recordings (blue) in response to spot-uncaging of glutamate $\left(\lambda_{\mathrm{u}}{ }^{2 \mathrm{p}}=720 \mathrm{~nm}, 20 \mathrm{~ms}\right.$ duration), at two distances from the astrocyte soma, as indicated; red lines, simulated whole-cell current in the corresponding model arrangement $(\sim 5 \mu \mathrm{m}$-wide glutamate application; GLT-1 kinetics ${ }^{67}$; GLT-1 surface density $10^{4} \mu \mathrm{m}^{-2}$ as estimated ${ }^{68}$ ). Plot, a summary of glutamate uncaging experiments (blue open dots, $\mathrm{n}=8$ cells / 90 uncaging spots) and uncaging tests simulated in the model (red solid dots, $n=39$ ).

f, Model snapshot $5 \mathrm{~ms}$ post glutamate spot-uncaging depicting the cell membrane current $(j$, left) voltage ( $V_{\mathrm{m}}$; right) landscape (example in Supplementary Movie 3); false colour scale. 


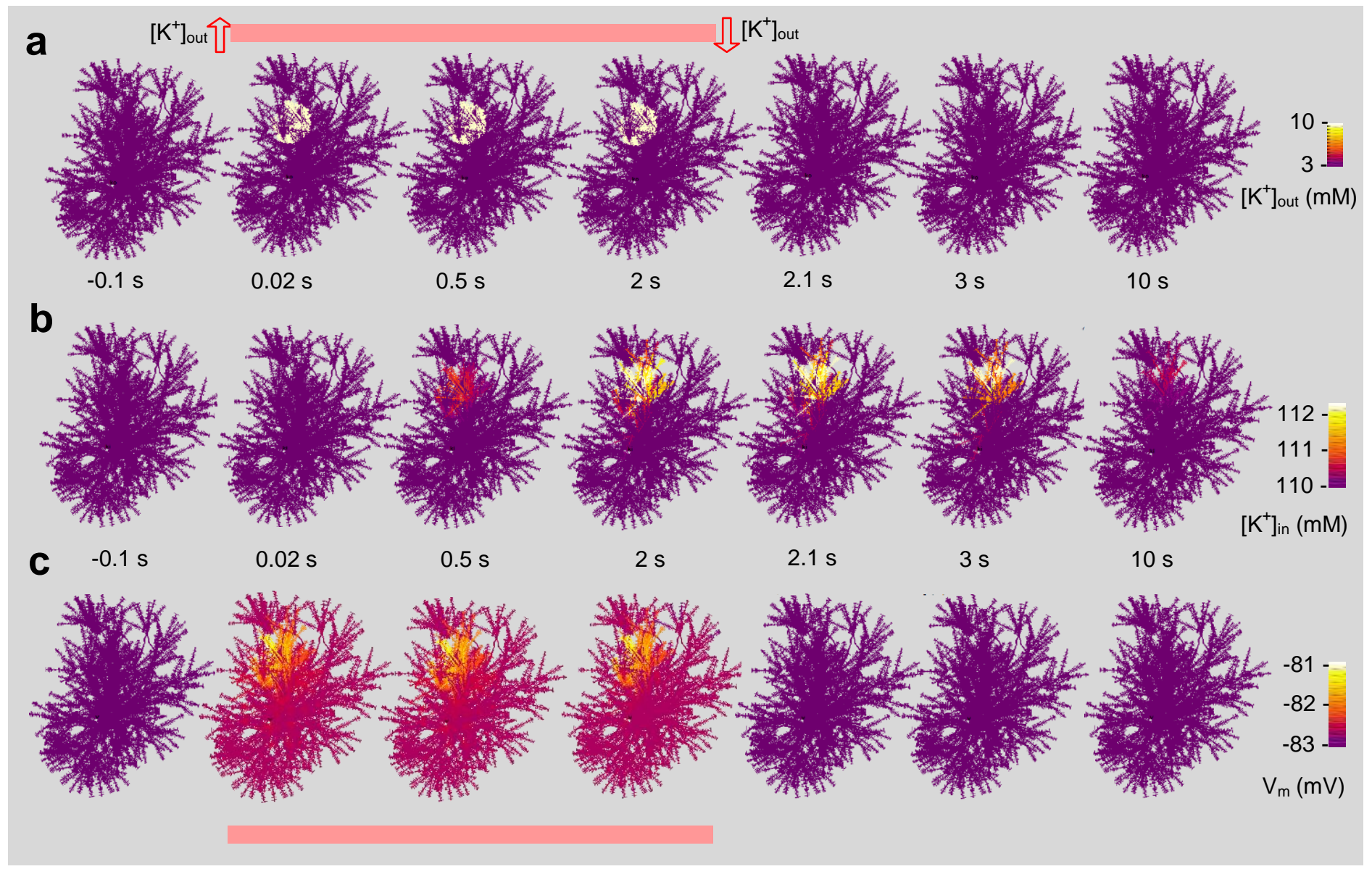

\section{Figure 5. Simulated dynamics of intracellular potassium and membrane voltage triggered by extracellular potassium rise.}

a, Cell shape diagrams, time series snapshots of the cell shape (3D-reconstruction reconstruction shown in Fig. 1a-d) illustrating a spherical $20 \mu \mathrm{m}$ wide area within which extracellular $\left[\mathrm{K}^{+}\right]_{\text {out }}$ was elevated form baseline $3 \mathrm{mM}$ to $10 \mathrm{mM}$, for 2 seconds (onset at $t=0$ ), as indicated; $\mathrm{K}_{\mathrm{ir}} 4.1$ channels were evenly distributed with unit conductance of $0.1 \mathrm{mS} / \mathrm{cm}^{2}$ generating peak current density (in the region with $\left[\mathrm{K}^{+}\right]_{\text {out }}=10 \mathrm{mM}$ ) of $0.01 \mathrm{~mA} / \mathrm{cm}^{2}$. The $\mathrm{K}_{\mathrm{ir}} 4.1$ kinetics were incorporated in NEURON, in accord with ${ }^{16}$, as:

$$
I_{K i r}=G_{K_{0}}^{*}\left[K^{+}\right]_{\text {out }}^{1 / 2}\left(V_{A}-V_{K A}-V_{A 1}\right)\left(1+\exp \left(\frac{V_{A}-V_{K A}-V_{A 2}}{V_{A 3}}\right)\right)^{-1}+I_{L A} \text { where } G_{K_{0}}^{*} \text { is the effective }
$$

conductance factor, $V_{K A}$ is the Nernst astrocyte $\mathrm{K}^{+}$potential, $V_{A}$ astrocyte membrane potential, $K_{0}$ is $\left[\mathrm{K}^{+}\right]_{\text {out }}, V_{A 1}$ an equilibrium parameter (sets $I_{K i r}$ to 0 at $-80 \mathrm{mV}$ ), $V_{A 2}$ and $V_{A 3}$ are constants calibrated by the $I-V$ curve, and $I_{L A}$ residual leak current.

b, Cell shape diagrams, snapshots illustrating the spatiotemporal dynamics of internal $\left[\mathrm{K}^{+}\right]_{\text {in }}$ in the test shown in a; false colour scale, as indicated.

c, Snapshots illustrating the spatiotemporal dynamics of the membrane voltage in the test shown in a; false colour scale, as indicated. 
bioRxiv preprint doi: https:/doi.org/10 1101/336974; this version posted June 17,2018. The copyright holder for this preprint (which was

a

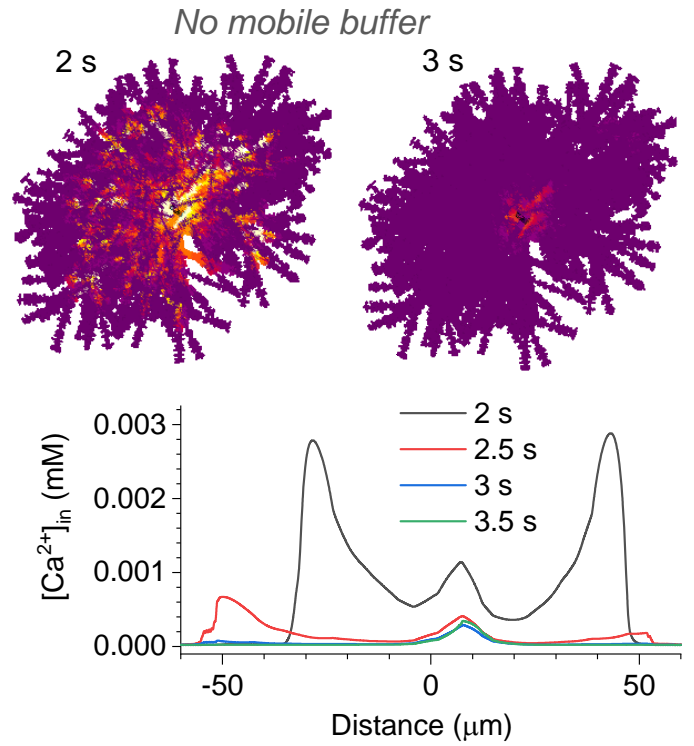

b

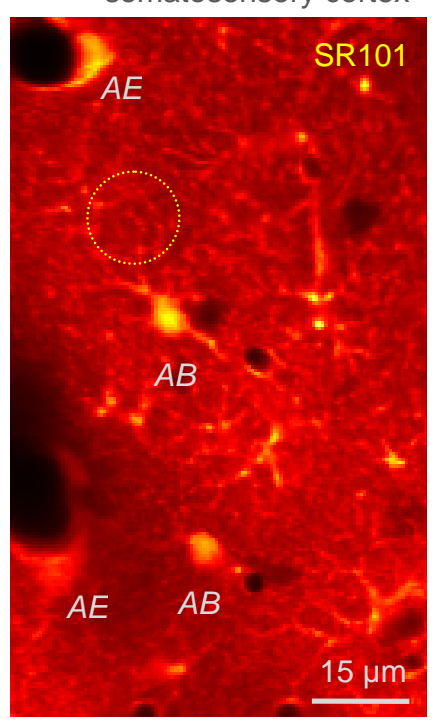

d

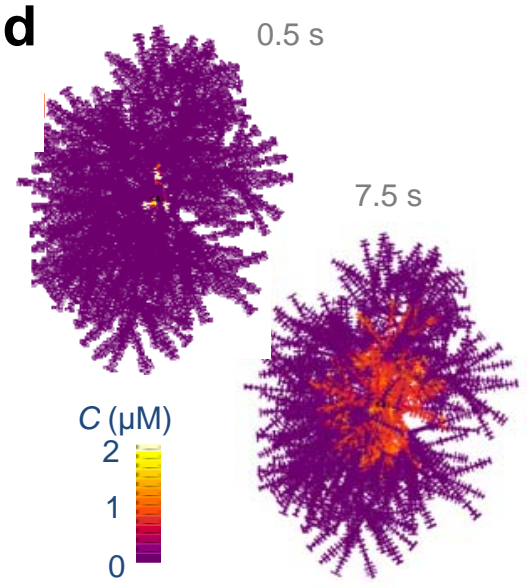

C
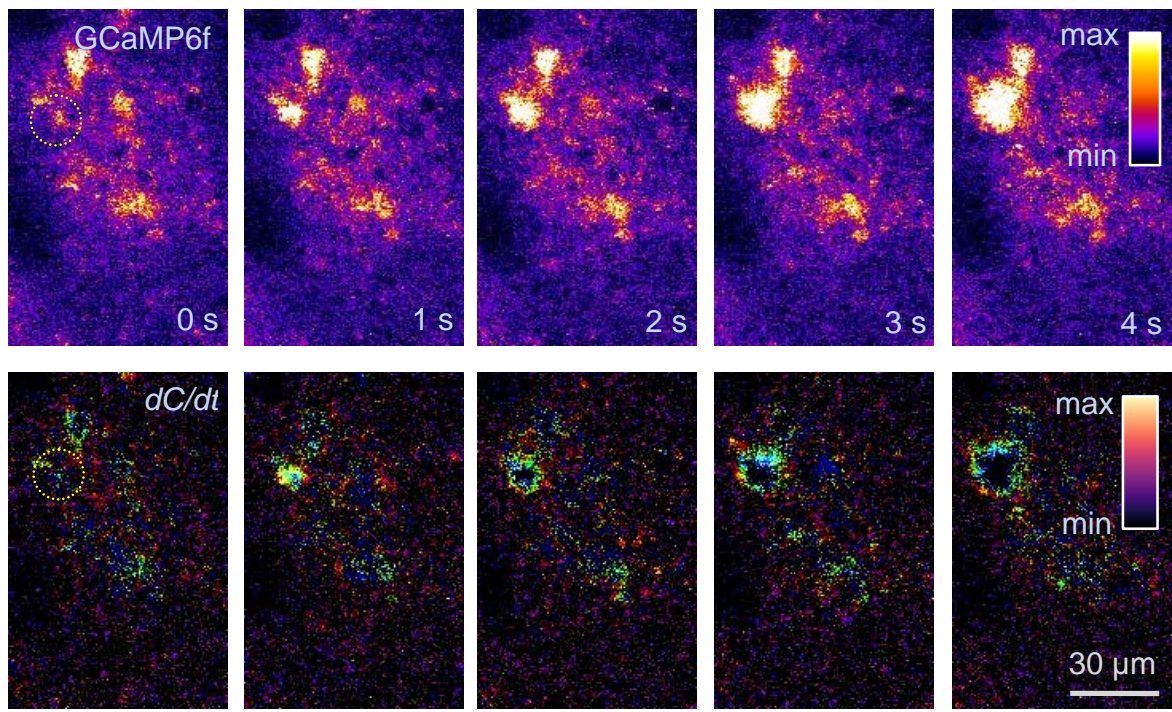

e
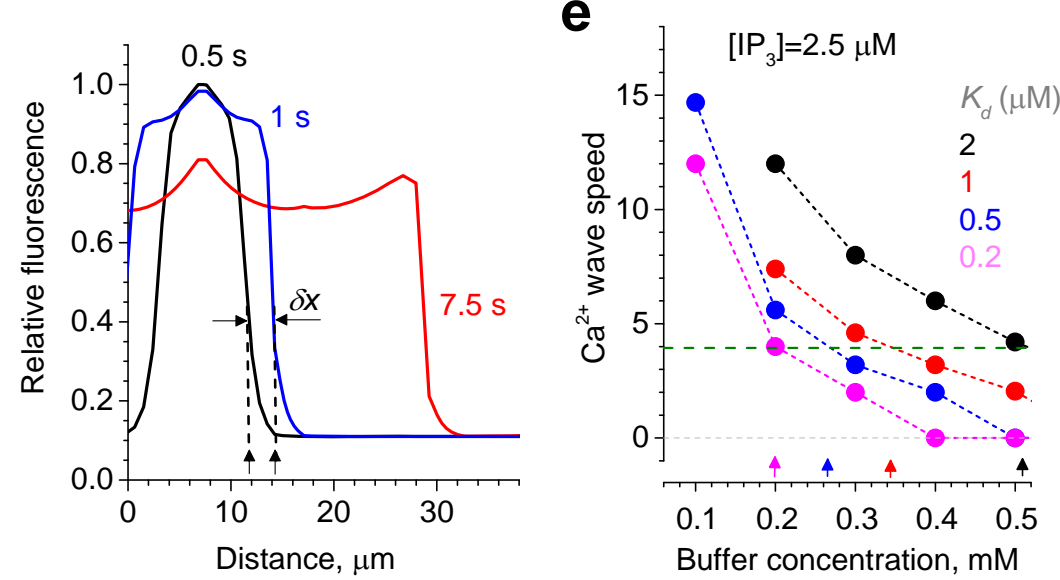

Figure 6. $\mathrm{Ca}^{2+}$ waves and $\mathrm{Ca}^{2+}$ buffering capacity of astrocytes. 
bioRxiv preprint doi: https://doi.org/10.1101/336974; this version posted June 17, 2018. The copyright holder for this preprint (which was not certified by peer review) is the author/funder, who has granted bioRxiv a license to display the preprint in perpetuity. It is made available under aCC-BY-NC-ND 4.0 International license.

a, Testing the basic effects of mobile $\mathrm{Ca}^{2+}$ buffers on $\mathrm{Ca}^{2+}$ wave generation in astroglia; cell diagrams, snapshots of $\left[\mathrm{Ca}^{2+}\right]$ landscape at time points after wave generation, with and without $\mathrm{Ca}^{2+}$ buffer, as indicated (note that some branches could obstruct full 3D view); graphs, evolution of the corresponding $\left[\mathrm{Ca}^{2+}\right]$ profiles (zero Distance, soma centre), as indicated. Relevant model parameters: $\mathrm{Ca}^{2+}$ diffusion coefficient, $0.3 \mu^{2} / \mathrm{ms}^{-1}$ immobile/endogenous $\mathrm{Ca}^{2+}$ buffer concentration, $200 \mu \mathrm{M}\left(\mathrm{K}_{\mathrm{f}}=1000 \mathrm{mM}^{-1} \mathrm{~ms}^{-1}\right.$; $\left.\mathrm{K}_{\mathrm{D}}=20 \mathrm{~ms}^{-1}\right)$; mobile Ca ${ }^{2+}$ buffer concentration, $10 \mu \mathrm{M}\left(\mathrm{K}_{\mathrm{f}}=600 \mathrm{mM}^{-1} \mathrm{~m}^{-1} ; \mathrm{K}_{\mathrm{D}}=0.5 \mathrm{~ms}^{-1}\right.$; diffusion coefficient $\left.0.05 \mu \mathrm{m}^{2} / \mathrm{ms}\right)$; $\mathrm{Ca}^{2+}$ pump activation threshold, $50 \mathrm{nM}$; $\mathrm{Ca}^{2+}$ pump flux density, $20 \mu \mathrm{M} / \mathrm{ms}$; basal $\mathrm{IP}_{3}$ concentration, $0.8 \mu \mathrm{M}$; $\mathrm{IP}_{3}$ concentration upon release, $5 \mu \mathrm{M}$; $\mathrm{IP}_{3}$ release onset time, $1 \mathrm{~s}$ (further detail in Supplementary ASTRO User Guide, Supplementary Movie 4).

b, 2PE image of the rat somatosensory cortex in vivo ( 100 $\mu \mathrm{m}$ deep); a single optical section shown with bulk-loaded sulforhodamine 101 (SR101, red channel) to label astroglial structures, as detailed earlier ${ }^{91}$; $A B$, examples of the astrocyte cell body; $A E$, examples of astrocyte endfoot processes surrounding blood vessels; see Supplementary Movies 1 and 2.

c, Region of interest (as in b) shown in the $\left[\mathrm{Ca}^{2+}\right]$-sensitive GGaMP6f (green) channel. Top, snapshot sequence (Supplementary Movie 4) depicting generation and spread of an intracellular $\mathrm{Ca}^{2+}$ wave (dotted circle); bottom, same sequence shown as the time derivative of fluorescence intensity (over $50 \mathrm{~ms}$ interval), to highlight the $\mathrm{Ca}^{2+}$ wave front; false colour scale. See Supplementary Movie 5 for awake-animal recording example.

d, Cell shape diagrams, snapshots of the simulated $\mathrm{Ca}^{2+}$ wave spreading with the speed that matches experimental observations; false colour scale ( $C$, concentration). Plot, the average intracellular $\left[\mathrm{Ca}^{2+}\right]$ profile depicting the corresponding (centrifugal) $\mathrm{Ca}^{2+}$ wave propagation; $\delta x$ illustrates the wave front speed measurement (distance travelled over $0.5 \mathrm{~s}$ ).

e, Summary of simulations depicted in $\mathbf{c}$, to determine the cytosol $\mathrm{Ca}^{2+}$ buffering capacity (combination of the buffer affinity $K_{d}$ and its concentration) that would explain the observed $\mathrm{Ca}^{2+}$ wave speed; [ $\left[\mathrm{IP}_{3}\right]$, assumed intracellular concentration of $\mathrm{IP}_{3}{ }^{88-90}$; dotted line, average experimental speed of centrifugal $\mathrm{Ca}^{2+}$ waves in astroglia in vivo, determined as in (a-b) $(\mathrm{n}=54$ events in approximately 20 individual cells). 

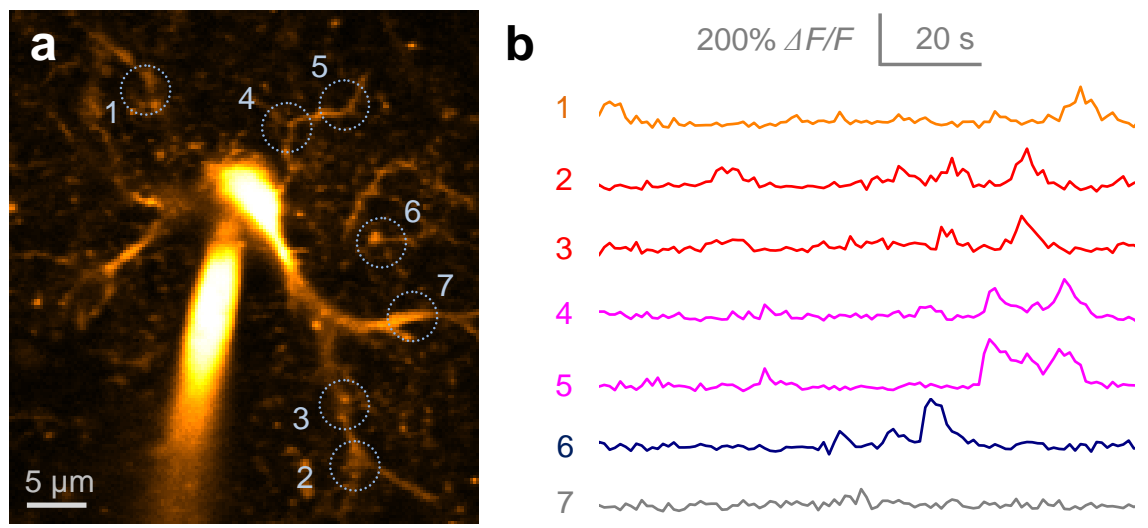

C

d

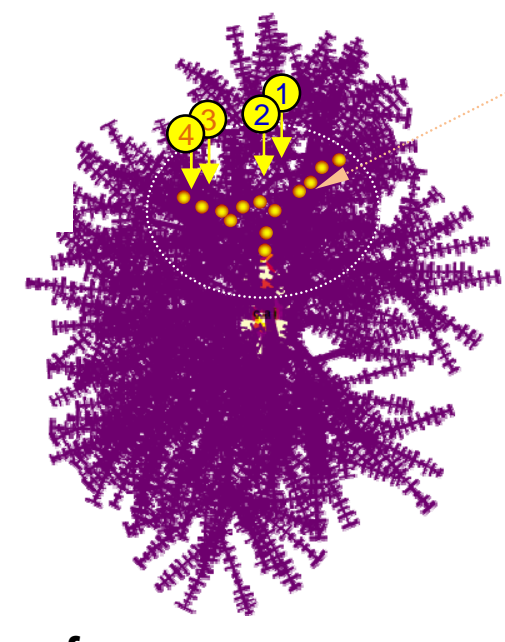

e
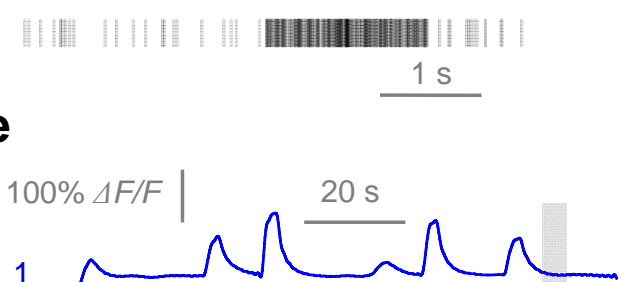

2

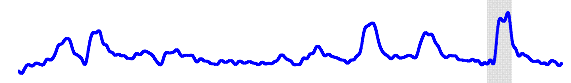

3

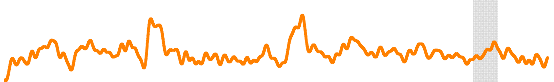

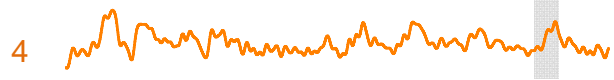

f

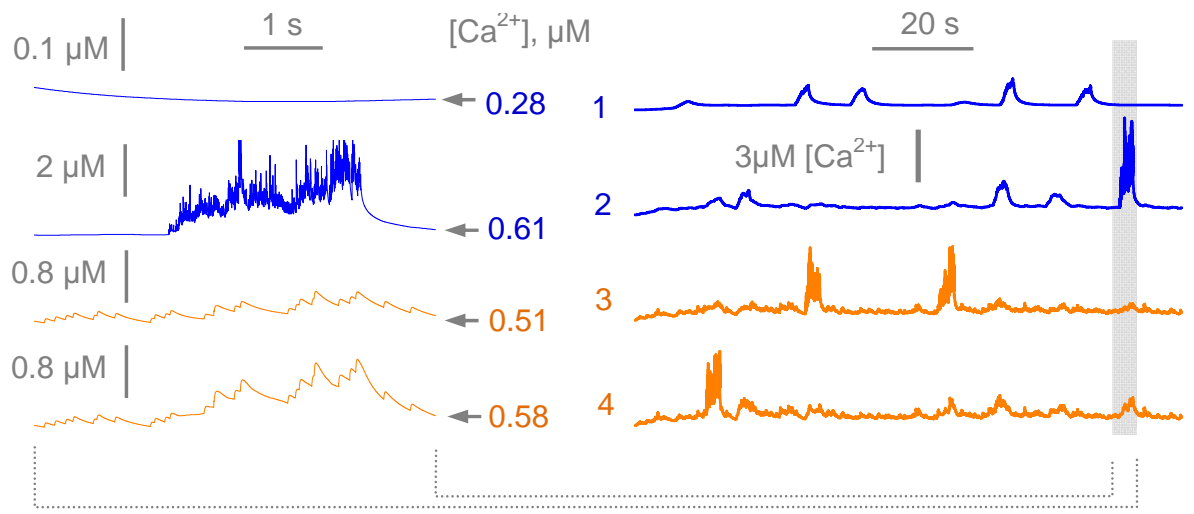

Figure 7. Deciphering intracellular free $\left[\mathrm{Ca}^{2+}\right]$ dynamics from fluorescence $\mathrm{Ca}^{2+}$ imaging in astroglia in situ.

a, Example, astrocyte (CA1 area, acute hippocampal slice; Fluo 4 channel, $\lambda_{\mathrm{x}}{ }^{2 \mathrm{P}}=800 \mathrm{~nm}$ ) held in whole-cell, with regions of interest for $\mathrm{Ca}^{2+}$ monitoring (circles, ROIs 1-7; Supplementary Movie 7). 
b, Time course of $\mathrm{Ca}^{2+}$ sensitive fluorescence (Fluo-4 channel) recorded in ROIs 1-7 as in a, over $100 \mathrm{~s}$; same colours correspond to ROIs on the same branch (ROIs 2-3 and 4-5).

c, An astrocyte model with localised $\mathrm{Ca}^{2+}$-puff sources (orange dots) and four recording points (arrows, 1-4); dotted oval, region for analyses: cell area outside has a negligible effect of the $\mathrm{Ca}^{2+}$ sources as shown (Supplementary Movie 8).

d, Example of channel-like local $\mathrm{Ca}^{2+}$ entry activity generated by a single localized $\mathrm{Ca}^{2+}$ source, in accord with the known biophysical properties of cellular $\mathrm{Ca}^{2+}$ sparks and hotspots ${ }^{30,104,109}$.

e, Time course of simulated Fluo-4 fluorescence (150 $\mu \mathrm{M}$ 'added') in ROIs 1-4 shown in c: it has statistical properties similar to those recorded in situ (b); shaded area, time window for higher temporal resolution (see f); same line colours correspond to ROIs on the same cell branch.

f, Right, simulated intracellular $\left[\mathrm{Ca}^{2+}\right]$ dynamics underlying Fluo-4 fluorescence shown in e; left, trace fragments on the expanded time scale (shaded area in $\mathbf{e}$ ), as indicated; the fragments correspond to the period of relatively high $\left[\mathrm{Ca}^{2+}\right]$. 
bioRxiv preprint doi: https://doi.org/10.1101/336974; this version posted June 17, 2018. The copyright holder for this preprint (which was not certified by peer review) is the author/funder, who has granted bioRxiv a license to display the preprint in perpetuity. It is made available under aCC-BY-NC-ND 4.0 International license.

\section{METHODS}

\section{Experimental methods: Electrophysiology ex vivo}

Acute hippocampal transverse slices (350 $\mu$ m thick) were prepared from P21-28 SpragueDawley rats, in full compliance with the national guidelines, the European Communities Council Directive of 24 November 1986 and the European Directive 2010/63/EU on the Protection of Animals used for Scientific Purposes. Slices were prepared in an ice-cold slicing solution containing (in $\mathrm{mM}$ ): $\mathrm{NaCl} 60$, sucrose 105, $\mathrm{NaHCO} 326, \mathrm{KCl} 2.5, \mathrm{NaH} 2 \mathrm{PO} 4$ 1.25, MgCl2 7 , $\mathrm{CaCl} 2$ 0.5, glucose 11, ascorbic acid 1.3 and sodium pyruvate 3 (osmolarity 300-310 mOsM), stored in the slicing solution at $34^{\circ} \mathrm{C}$ for $15 \mathrm{~min}$ and transferred for storage in an extracellular solution containing (in $\mathrm{mM}$ ): $\mathrm{NaCl} 125, \mathrm{NaHCO} 326, \mathrm{KCl} 2.5, \mathrm{NaH} 2 \mathrm{PO} 41.25, \mathrm{MgSO} 4$ 1.3, $\mathrm{CaCl} 22$ and glucose 16 (osmolarity 300-305 mOsm). All solutions were continuously bubbled with $95 \%$ O2/5\% CO2. Slices were allowed to rest for at least $60 \mathrm{~min}$ before recordings started.

Whole-cell patch-clamp recordings of stratum radiatum astroglia were performed in a submersion-type recording chamber. Slices were superfused with an extracellular solution containing (in mM): $\mathrm{NaCl} 125, \mathrm{NaHCO} 3$ 26, $\mathrm{KCl}$ 2.5, NaH2PO4 1.25, MgSO4 1.3, CaCl2 2 and glucose 16 (osmolarity 300-305 mOsm), continuously bubbled with 95\% O2/5\% CO2. Wholecell recordings were obtained with patch pipettes (3-5 $\mathrm{M} \Omega$ ) with an intracellular solution containing (in mM): $\mathrm{KCH} 3 \mathrm{O} 3 \mathrm{~S}$ 135, HEPES 10, Tris-phosphocreatine 10, $\mathrm{MgCl} 2$ 4, Na2ATP 4, Na3GTP 0.4 (pH adjusted to 7.2 with $\mathrm{KOH}$, osmolarity 290-295 mOsM). The cell impermeable $\mathrm{Ca} 2+$ indicator OGB-1 (200 $\mu \mathrm{M}$ unless indicated otherwise; Invitrogen O6806) was added to the internal solution. CA1 pyramidal cells were held at $-70 \mathrm{mV}$. Protoplasmic astrocytes located in the stratum radiatum were identified by their small soma size, low resting potential $(<-80 \mathrm{mV})$ and low input resistance $(<10 \mathrm{M} \Omega)$. Astrocytes were held in voltage clamp at their resting potential or in current clamp.

In some experiments, whole-cell patches were excised by pulling gently the patch pipette attached to the cell body until the patch was completely detached from the processes and its membrane sealed. Estimation of the patch capacitance $c$ was carried out using a classical voltage-step method in which (a) a brief voltage step $\Delta V$ is applied, (b) the area under the transient capacitance current after the end of the voltage step is measured, giving electric charge $Q$, and (c) membrane patch capacitance is estimated as $c=Q / \Delta V$. Thus the patch area is evaluated from the ratio $c / c_{\mathrm{m}}$ where specific membrane capacitance $c_{\mathrm{m}}=1 \mu \mathrm{F} / \mathrm{cm}^{2}$ is a common characteristic of astroglial membranes ${ }^{18}$. The steady-state current response to the voltage step was used to calculate the patch conductance, which was then normalized to the membrane area to obtain $\mathrm{G}_{\mathrm{m}}$.

\section{Experimental methods: 2PE imaging, uncaging, and FRAP ex vivo}

Astrocytes were filled via whole-cell patch clamp with 40-100 $\mu \mathrm{M}$ Alexa Fluor 594 for 15-20 min. We used an Olympus FV1000 imaging system optically linked to a femtosecond pulse Tisapphire MaiTai laser (Newport Spectra-physics). Cells were imaged using an Olympus XLPlan $\mathrm{N} 25 \mathrm{x}$ water immersion objective. Fluorescence recordings were obtained in line-scan mode $(500 \mathrm{~Hz}$, line placed through the astrocyte arbour and across the soma) at $\lambda=800 \mathrm{~nm}$ at an increased laser power of 15-20 mW under the objective to induce substantial bleaching of Alexa Fluor 594. Fluorescence was collected for 750-1000 ms, then a mechanical shutter was placed in front of the laser beam for 1-2 s to allow fluorescence recovery.

We used a combined two-photon uncaging and imaging microscope (Olympus, FV-1000MPE) powered by two Ti:Sapphire pulsed lasers (Chameleon, Coherent, tuned to $720 \mathrm{~nm}$ for uncaging and MaiTai, Spectra Physics, tuned to $800 \mathrm{~nm}$ for imaging). Cells were imaged using an 
bioRxiv preprint doi: https://doi.org/10.1101/336974; this version posted June 17, 2018. The copyright holder for this preprint (which was not certified by peer review) is the author/funder, who has granted bioRxiv a license to display the preprint in perpetuity. It is made available under aCC-BY-NC-ND 4.0 International license.

Olympus XLPlan N 25x water immersion objective. The intensity of the imaging and uncaging laser beams under the objective was set to $5 \mathrm{~mW}$ and $12-17 \mathrm{~mW}$, respectively.

To record spontaneous Ca2+ transients in frame scan mode, $200 \mu \mathrm{M}$ Fluo-4 (Invitrogen) and 100 $\mu \mathrm{M}$ Alexa Fluor 594 (Invitrogen) were added to the intracellular solution. 350-500 $\mu \mathrm{m}^{2}$ fields of view where imaged within the arbour of the patched astrocyte and the fluorescence emitted by Alexa Fluor 594 and Fluo-4 was collected at a rate of 3-5 Hz for 2-3 min. Time-dependent fluorescence transients were expressed as $\Delta \mathrm{G} / \mathrm{R}$ where $\mathrm{G}$ corresponds to the backgroundsubtracted Fluo-4 fluorescence and R to the background-subtracted Alexa Fluor 594 fluorescence.

For MNI-glutamate uncaging, astrocytes were loaded with $100 \mu \mathrm{M}$ Alexa Fluor 594 as a morphological marker. Astrocytes were held in voltage-clamp mode at their resting membrane potential (typically between -80 and $-90 \mathrm{mV})$. The MNI-glutamate $(12.5 \mathrm{mM}$ ) was either puffed within the tissue from a glass pipette placed above the patched cell, or added to the bath at 2.5 $\mathrm{mM}$. Glutamate was uncaged for $20 \mathrm{~ms}$ at different distances from the soma $(5-25 \mu \mathrm{m})$.

\section{Experimental methods: 3D reconstruction of live astrocyte stem tree}

A stratum radiatum astrocyte was held in whole-cell mode, with Alexa Fluor 594 added to the intracellular solution (see above; excitation at $\lambda_{\mathrm{x}}{ }^{2 \mathrm{p}}=800 \mathrm{~nm}$ ). A $z$-stack of $2 \mathrm{PE}$ images was collected using $100 \times 100 \mu \mathrm{m}(512 \times 512$ pixel) individual frames containing the entire visible astrocyte structure, with a $0.5 \mu \mathrm{m} z$-step over $61 \mu \mathrm{m}$ in depth. The image stack was stored (8-bit tiff format), individual images were corrected for the depth-dependent, quasi-exponential fluorescence signal decrease (Fiji Image-Adjust-Bleach Correction, plugin by Kota Miura 2014: 10.5281/zenodo.30769). Fluorescence background was subtracted (Fiji Image-Process), identifiable cell branches ( $>0.3-0.5 \mu \mathrm{m}$ in diameter) were traced semi-automatically in individual 2D optical sections and reconstructed in 3D using Neurite Tracer (Fiji PluginsSegmentation-Simple Neurite Tracer; by Mark Longhair and Tiago Ferreira, MRC and Janelia Campus; http://imagej.net/Simple_Neurite_Tracer; default segmentation sigma, 0.196). The data sets representing diameters of tubular compartments and their 3D co-ordinates (pairs of end points) were stores in SWC format. The Vaa3D software (Allen Institute, http://www.alleninstitute.org/what-we-do/brain-science/research/products-tools/vaa3d/) was used to convert these data sets into NEURON compatible files providing 3D structure of the astroglia stem-tree (with tubular compartments representing individual cylindrical compartments).

\section{Experimental methods: Astroglia-targeted expression of GCaMP6f in vivo}

Animal procedures were conducted in accordance with the European Commission Directive (86/609/ EEC) and the United Kingdom Home Office (Scientific Procedures) Act (1986). Young male C57BL/6 mice ( 2 - 3 weeks of age) were anaesthetised using isoflurane (5\% induction, 1.5 $-2.5 \% \mathrm{v} / \mathrm{v}$ ). Subcutaneous analgesic (buprenorphine, $60 \mu \mathrm{g} \mathrm{kg}^{-1}$ ) was administered and the animal was secured in a stereotaxic frame (David Kopf Instruments, CA, USA) and kept warm on a heating blanket. The scalp was shaved and disinfected using three washes of topical chlorhexidine. Upon loss of pedal withdrawal reflexes, a small midline incision was made to expose the skull. A craniotomy of approximately $1-2 \mathrm{~mm}$ diameter was performed over the right somatosensory cortical region using a high-speed hand drill (Proxxon, Föhren, Germany). Stereotactic coordinates were $+0.1 \mathrm{~mm}$ on the anterioposterior axis relative to bregma, and $2 \mathrm{~mm}$ lateral to midline. Once exposed, a warmed aCSF variant (cortex buffer, in $\mathrm{mM} ; 125 \mathrm{NaCl}, 2.5$ $\mathrm{KCl}, 10 \mathrm{HEPES}, 10$ glucose, $2 \mathrm{CaCl}_{2}, 2 \mathrm{MgSO}_{4}$ ) was applied to the skull and cortical surface throughout the procedure. 
bioRxiv preprint doi: https://doi.org/10.1101/336974; this version posted June 17, 2018. The copyright holder for this preprint (which was not certified by peer review) is the author/funder, who has granted bioRxiv a license to display the preprint in perpetuity. It is made available under aCC-BY-NC-ND 4.0 International license.

AAV5 GfaABC1D-LckGCaMP6f (Penn Vector Core, PA, USA) was pressure injected into the somatosensory cortex using a pulled glass micropipette stereotactically guided to a depth of 0.6 $\mathrm{mm}$ beneath the pial surface, at a rate of approximately $1 \mathrm{~nL} \mathrm{sec}{ }^{-1}$. A given injection bolus contained between 0.25 and $0.5 \times 10^{10}$ genomic copies, in a volume not exceeding $500 \mathrm{~nL}$. After injection, pipettes were left in place for 5 minutes before retraction. The scalp was sutured with absorbable 7-0 sutures (Ethicon Endo-Surgery GmbH, Norderstedt, Germany) and the animal was left to recover in a heated chamber. Meloxicam (subcutaneous, $1 \mathrm{mg} \mathrm{kg}^{-1}$ ) was administered once daily for up to two days following surgery. After a 4 - 6 week AAV incubation period, animals were prepared for multiphoton imaging through a cranial window implantation as described below.

\section{Experimental methods: Two-photon excitation imaging of astroglia in vivo}

Following viral transduction of LckGCaMP6f as above, male C57BL/6 mice (7-9 weeks of age) were prepared for cranial window implantation and 2PE microscopy. Animals were anesthetized using fentanyl, midazolam and medetomidine (i.p., $0.05,5$ and $0.5 \mathrm{mg} \mathrm{kg}^{-1}$, respectively). Adequate anesthesia was ensured by continuously checking for the loss of pedal withdrawal reflexes and anaesthesia was supplemented appropriately throughout the procedure (typically 10$20 \%$ of the original dose per hour). Body temperature was maintained at $37.0 \pm 0.5^{\circ} \mathrm{C}$ using a feedback rectal thermometer and heating blanket. The animal was secured in a stereotaxic frame and a craniotomy of approximately $2.5 \mathrm{~mm}$ diameter was carried out over the right somatosensory cortex, centred $0.2 \mathrm{~mm}$ caudal to bregma and approximately $2.5 \mathrm{~mm}$ laterally from the midline. Once exposed, the cortical surface was continuously superfused with warmed aCSF (in mM; $125 \mathrm{NaCl}, 2.5 \mathrm{KCl}, 26 \mathrm{NaHCO}_{3}, 1.25 \mathrm{Na}_{2} \mathrm{HPO}_{4}, 18$ Glucose, $2 \mathrm{CaCl}_{2}, 2 \mathrm{MgSO}_{4}$; saturated with $95 \% \mathrm{O}_{2} / 5 \% \mathrm{CO}_{2}, \mathrm{pH} 7.4$ ). Cortical astrocytes were labeled using multicell bolus loading of sulforhodamine 101 (SR101, $5 \mu \mathrm{M})$. SR101 (in cortex buffer vehicle) was pressureinjected through a pulled glass micropipette targeted to $2-3$ injection sites within the transduced region, comprising a total volume of $500 \mathrm{~nL}$. The cortical surface was covered with $1 \%$ agarose and a glass coverslip was placed on top. Using tissue adhesive (Dermafuse, Vet-Tech Solutions, UK), the coverslip was partially secured and a custom-built headplate fixed to the skull. A single cranial-mounted screw was inserted over the contralateral hemisphere and the entire assembly was then secured using dental cement. During imaging, the headplate was used to secure the animal under the objective on a custom-built stage.

In these experiments, two-photon excitation was carried out using a Newport-Spectraphysics Ti:sapphire MaiTai laser pulsing at $80 \mathrm{MHz}$, and an Olympus FV1000 with XLPlan N 25x water immersion objective (NA 1.05). Acquisitions were carried out using a wavelength of $920 \mathrm{~nm}$ and the mean laser power under the objective was kept at $20-35 \mathrm{~mW}$. Cortical astrocytes were readily identified through SR101 labeling and verified for GCaMP6f expression by framescanning for calcium transient activity. Recordings were made at a depth between 50 and 250 $\mu \mathrm{m}$ from the cortical surface. XY time series (at $0.5-2 \mathrm{~Hz}$ with a pixel dwell time of $0.5-4 \mu \mathrm{s}$ and pixel size of $0.248-1.59 \mu \mathrm{m}$ ) were taken in identified regions to measure spontaneous calcium activity.

\section{Experimental methods: Fast fixation and DAB staining of recorded astrocytes}

In a subset of experiments we loaded an astrocyte with biocytin, and after the experiment the slices were rapidly fixed (by submersion) with $1.25 \%$ glutaraldehyde and $2.5 \%$

paraformaldehyde in $0.1 \mathrm{M} \mathrm{PB}$ (phosphate buffer, $\mathrm{pH}$ 7.4), to be kept overnight, submerged in $10 \%$ sucrose in PB for 10 min and then in $20 \%$ sucrose in PB for 30 min. The slices were consequentially freeze-thaw in liquid freon and liquid nitrogen for $3 \mathrm{sec}$ each to gently crack intracellular membranes and embedded in $1 \%$ low gelling temperature agarose in PB (SigmaAldrich, USA). Embedded slices were sectioned at $50 \mu \mathrm{m}$ on a vibrating microtome (VT1000; 
bioRxiv preprint doi: https://doi.org/10.1101/336974; this version posted June 17, 2018. The copyright holder for this preprint (which was not certified by peer review) is the author/funder, who has granted bioRxiv a license to display the preprint in perpetuity. It is made available under aCC-BY-NC-ND 4.0 International license.

Leica, Milton Keynes, UK). $50 \mu \mathrm{m}$ sections were incubated in $1 \% \mathrm{H}_{2} \mathrm{O}_{2}$ in PB for 20 min to eliminate blood background, washed with $0.1 \mathrm{M}$ TBS (tris buffer saline, $\mathrm{pH}$ 7.4) and incubated with ABC solution (VECTASTAIN ABC, Vector laboratories, USA) for $30 \mathrm{~min}$ at room temperature. Next section were washed with $0.1 \mathrm{M}$ TB (tris buffer, $\mathrm{pH}$ 7.4), pre-incubated with DAB (3,3'-Diaminobenzidine tablets - Sigma-Aldrich, USA) solution (10 mg DAB tablet +40 $\mathrm{ml} \mathrm{TB}$ ) for $30 \mathrm{~min}$ at room temperature in dark and finally incubated with $\mathrm{DAB}+\mathrm{H} 2 \mathrm{O} 2$ solution ( $5 \mu \mathrm{l}$ of $33 \% \mathrm{H}_{2} \mathrm{O}_{2}+25 \mathrm{ml}$ of DAB solution) for $10-20 \mathrm{~min}$ at room temperature in dark. The $\mathrm{DAB}$ stained sections was washed in $\mathrm{PB}$, post-fixed in $2 \%$ osmium tetroxide and further processing and embedding protocols were essentially similar to those reported previously (Medvedev et al., 2010). Briefly, the tissue was dehydrated in graded aqueous solutions of ethanol (40 - 100\%) followed by 3 times in $100 \%$ acetone, embedded into a mixture of $50 \%$ epoxy resin (Epon 812/Araldite M) and 50\% acetone for $30 \mathrm{~min}$ at room temperature, embedded in pure epoxy resin, and polymerized overnight at $80^{\circ} \mathrm{C}$. Sections in blocks were coded and all further analyses were carried out blind as to the experimental status of the tissue.

\section{Experimental methods: 3D electron microscopy}

Serial sections (60-70 nm thick) were cut with a Diatome diamond knife as detailed and illustrated earlier ${ }^{111,112}$, and systematically collected using Pioloform-coated slot copper grids (each series consist of up to 100 serial sections). Sections were counterstained with $4 \%$ uranyl acetate, followed by lead citrate. Finally sections were imaged in stratum radiatum area of CA1 (hippocampus) using AMT XR60 12 megapixel camera in JEOL 1400 electron microscope. Serial sections were aligned as JPEG images using SEM align 1.26b (software available from http://synapses.clm.utexas.edu/). 3D reconstructions of DAB stained astrocyte fragments and the adjoined to stained astrocytes dendritic spines (that host clearly identifiable excitatory synapses) were performed in Trace 1.6b software (http://synapses.clm.utexas.edu/). 3D reconstructions of selected astrocytic segments and dendritic spines were imported to 3D-StudioMax 8 software for rendering of the reconstructed structures.

\section{Statistics summary}

The present study contained no longitudinal or multifactorial experimental designs. In electrophysiological or imaging experiments the main source of biological variance in were either individual cells or individual preparations (the latter in case of field measurements in acute slices), as indicated. In accord with established practice, in the ex vivo tests we routinely used one cell per slice per animal, which thus constituted equivalent statistical units in the context of sampling, unless indicated otherwise. Statistical hypotheses pertinent to mean comparisons were tested using a standard two-tailed t-test, unless the sample showed a significant deviation from Normality, in which case non-parametric tests were used as indicated. The null-hypothesis rejection-level was set at $\alpha=0.05$, and the statistical power was monitored to ensure that that the sample size and variance were adequate to detect a mean difference (in two-sample comparisons) of $10-15 \%$ or less.

\section{Astrocyte model: generating 'invisible' nanoscopic morphology}

Nanoscopic processes of the astrocyte model are generated in a probabilistic manner based on the sample statistics from 3D EM reconstructions (Fig. 2). The total cell surface area $S_{\text {tot }}$ represented by the cylinder-based shape approximations (Fig. 2d,e), consists of the (lateral) surface areas of all cylinder-compartment sides $S_{l a t}$ added to the surface areas of 'main' cylinder bases $S_{M}$ (blue in Fig. 2d, bottom) minus the surface areas of 'transitional' cylinder bases $S_{T}$ (green in Fig. 2d, bottom). In our case study, computations indicated that $S_{T}=0.20 S_{M}$ throughout modelling: thus, the formula $S_{t o t}=S_{l a t}+0.8 S_{M}$ was applied. In the generated cell models, the S/V 
bioRxiv preprint doi: https://doi.org/10.1101/336974; this version posted June 17, 2018. The copyright holder for this preprint (which was not certified by peer review) is the author/funder, who has granted bioRxiv a license to display the preprint in perpetuity. It is made available under aCC-BY-NC-ND 4.0 International license.

ratios were ranging from $\sim 7 \mu \mathrm{m}^{-1}$ near the soma to an average of $\sim 22 \mu \mathrm{m}^{-1}$ in the bulk of the cell arbour, in accord with the empirical observations.

\section{Astrocyte model: transporter/channel kinetics and diffusion-reaction mechanisms}

Models built with ASTRO can incorporate many dozens of NEURON-enabled channel and transporter kinetic mechanisms that have been tested and validated in numerous studies combining experiments and simulations ${ }^{24}$. The formal descriptions of the respective algorithms could be found using an extensive NEURON database at https://senselab.med.yale.edu/modeldb/ which also contains references and links to the original studies and the mathematical formulism involved. Upon ASTRO installation on the host computer, these mechanisms could also be inspected in the respective *.mod files in the 'neuronsims' directory or, alternatively, online here https://github.com/LeonidSavtchenko/Astro/tree/master/neuronSims.

Several channel current and diffusion-reaction mechanisms have been written specifically for the present model. The kinetics of glutamate transporter GLT-1 involving glutamate and ion fluxes has been incorporated in accordance with ${ }^{113}$ (description in the GluTrans.mod file). The $\mathrm{K}_{\mathrm{ir}} 4.1$ potassium current has been incorporated in accordance with ${ }^{16}$ (Kir4.mod; Fig. 5 legend), intracellular $\mathrm{K}^{+}$diffusion was incorporated as longitudinal diffusion (no radial rings) using a built-in $\mathrm{Ca}^{2+}$ diffusion algorithm described in the next section (potassium.mod), the FRAP mechanism incorporated the same algorithm plus a reaction-diffusion step (FRAP.mod), and $\mathrm{K}^{+}$ extrusion was modelled as a first-order pump (kpump.mod; Supplementary Fig. xx legend). Gap junction mechanisms were enabled either as a (zero-order) current leak (gap.mod) or as a diffuse escape (gapCa.mod). Throughout these mechanisms, the respective kinetic parameters can be set using the relevant NEURON-enabled ASTRO menus, as described in the User Guide (https://github.com/LeonidSavtchenko/Astro/blob/master/ASTRO_User_Guide.pdf).

\section{Astrocyte model: $\mathrm{Ca}^{2+}$ homeostasis and diffusion}

ASTRO simulation algorithms enabling intracellular $\mathrm{Ca}^{2+}$ homeostasis and diffusion (including that among adjacent compartments of unequal size) are detailed in Chapter 9 of the NEURON Book $^{24}$ (also here https://www.neuron.yale.edu/neuron/docs), and can be found in the modified cadifus.mod file in the model installation. In brief, $\mathrm{Ca}^{2+}$ diffuses freely whereas buffer-bound $\mathrm{Ca}^{2+}$ (which has much lower diffusivity) is considered stationary, for the sake of simplicity. In individual cylindrical cell compartments, radial diffusion occurs through four concentric shells surrounding a cylindrical central core, and longitudinal diffusion is calculated using fluxes between the corresponding concentric compartments adjusted for the cross-section areas. The longitudinal and radial diffusion coefficient for $\mathrm{Ca}^{2+}$ was set to $0.3 \mu \mathrm{m}^{2} \mathrm{~ms}^{-1}$, the basal level was set to $50 \mathrm{nM}$, and $\mathrm{IP}_{3}$ concentration at 0 .

In addition to free diffusion, $\mathrm{Ca}^{2+}$ homeostasis mechanisms included the SERCA pump, SERCA channel and SERCA leak, the endogenous (stationary) and exogenous ( $\mathrm{Ca}^{2+}$ indicator) mobile buffers, and a plasma membrane $\mathrm{Ca}^{2+}$ pump with the threshold mechanism (cadifus.mod). The kinetics of buffers can be modified using NEURON-enabled menus. The mechanistic details of $\mathrm{Ca}^{2+}$ SERCA pump were as described earlier ${ }^{87,114}$. The current model implementation assumes that $\mathrm{IP}_{3}$ is distributed uniformly across cell compartments, i.e. that diffusion equilibration of $\mathrm{IP}_{3}$ is fast compared to $\mathrm{Ca}^{2+}$ concentration transients in space or time.

\section{Modelling with ASTRO: On-line access and installation}

Detailed information on the installation and running of ASTRO can be found in the User's Manual (Supplementary Material; online download at https://github.com/LeonidSavtchenko/Astro/blob/master/Manual). The current version of ASTRO can also be downloaded directly from https://github.com/LeonidSavtchenko/Astro. The 
(regularly updated) User Guide can be downloaded from the same location or found (current version) in the Supplementary Information (User_Guide.doc).

In brief, running ASTRO without full-scale simulations of intracellular $\mathrm{Ca}^{2+}$ dynamics requires the host computer to have MATLAB (2012 version or later, https://uk.mathworks.com/products/matlab.html ) and NEURON (7.2 or later, https://neuron.yale.edu/neuron/download) installed under Windows 7 or Windows 10.

Simulating full intracellular $\mathrm{Ca}^{2+}$ dynamics is highly resource-consuming and normally requires an additional Worker computer / cluster operating under Linux, with preinstalled NEURON (https://neuron.yale.edu/neuron/download/compile_linux) and MPI whereas the Host computer will require MATLAB (2013 version or later), NEURON (7.0 or later), and access to the Internet. In house, the Linux version with the parallel computations including intracellular diffusion simulation was routinely run using a 12 -node in-house computer cluster ${ }^{115}$, taking advantage of the computational optimization routines developed by us earlier for compartmental models and Monte Carlo simulations ${ }^{52,53,115}$. 